\title{
How does the U.S. government finance fiscal shocks?
}

\author{
Antje Berndt ${ }^{\mathrm{a}}$, Hanno Lustig ${ }^{\mathrm{b}}$, Şevin Yeltekin ${ }^{\mathrm{a}}$ \\ ${ }^{a}$ Tepper School of Business, Carnegie Mellon University, Pittsburgh, PA \\ ${ }^{b}$ Anderson School of Management, UCLA, Los Angeles, CA and NBER
}

\begin{abstract}
We develop a method for identifying and quantifying the fiscal channels that help finance government spending shocks and apply it to postwar U.S. data. We define fiscal shocks as surprises in defense spending and show that they are more precisely identified when defense stock data are used in addition to aggregate macroeconomic data. Our results show that in the postwar period, over 9\% of the U.S. government's unanticipated spending needs were financed by a reduction in the market value of debt and more than $73 \%$ by an increase in primary surpluses. We provide evidence that longer maturity debt is more effective at absorbing fiscal risk and discuss the implications of this result for active management of public debt.
\end{abstract}

Keywords: Fiscal shocks, fiscal adjustment, defense spending, bond returns, debt management

JEL: C5, E4, E6, G1, H6

\section{Introduction}

In this paper we explore the dynamic adjustment of the U.S. government's fiscal balances to expenditure shocks. We identify the different fiscal adjustment channels that help stabilize the U.S. government's balances and develop a method for quantifying the use of each channel in the postwar era. To do so, we make use of the government's intertemporal

\footnotetext{
"We would like to thank seminar participants at the Federal Reserve Bank of Chicago, Federal Reserve Bank of Cleveland, University of Warwick, Harvard University, Rice University, Wharton and NYU-Stern for comments. We would also like to thank George Hall for sharing his data with us. Batchimeg Sambaliat provided excellent research assistance.
}

April 23, 2010 
budget constraint. The government's budget constraint dictates that surprise increases in spending must be financed through either an increase in primary surpluses or a reduction in returns on the government's bond portfolio. We refer to the first channel of adjustment as the surplus channel and the second as the debt valuation channel.

The surplus channel operates through an increase in contemporaneous and expected future surplus growth when the news about higher expenditures are revealed whereas the debt valuation channel operates through a decline in contemporaneous and expected future debt returns. In normative models of fiscal policy, adjustments through the debt valuation channel are referred to as "fiscal insurance". Standard models in this literature feature a benevolent government that minimizes the excess burden of taxation by varying its debt returns. The extent to which it can do this is determined by the asset market structure it faces. In complete-market models, a decline in debt returns absorbs the surprise increase in spending needs, allowing the government to maintain a constant excess burden of taxation. In incomplete-market models, however, interstate financing of fiscal shocks, hence fiscal insurance through bond markets, is limited. ${ }^{1}$

Several authors have used the implications of these normative models and the empirical behavior of tax rates and debt levels to assess the incompleteness of debt markets. ${ }^{2}$ The empirical evidence uncovered and documented in these papers suggests that debt markets are incomplete and hence do not provide full insurance against fiscal shocks. However, the prior literature does not quantify how much fiscal insurance the government does achieve through bond markets in practice. ${ }^{3}$ Our main contribution is to develop a framework for identifying fiscal adjustment channels and to provide quantitative estimates of fiscal insurance. This is accomplished by using the intertemporal budget constraint of the government only, and hence without taking an a priori stance on market incompleteness or government preferences.

To quantify the degree of fiscal adjustment through each channel, we proceed in three

\footnotetext{
${ }^{1}$ See Section 2.2 for references and a more thorough discussion of normative models.

${ }^{2}$ See, inter alia, Barro (1979), Gourinchas and Rey (2007), Scott (2007) and Marcet and Scott (2009).

${ }^{3}$ One exception is Faraglia, Marcet, and Scott (2008a), who report covariances between deficit shocks and value of debt for a select group of OECD countries between 1970 and 2000.
} 
steps. The first step involves the log-linearization of the government's budget constraint which permits a tractable decomposition of the response to fiscal shocks into news about current and future surplus growth and news about current and future debt returns. Motivated by Ramey (2009)'s discussion that defense spending accounts for almost all of the volatility of government spending, we identify fiscal shocks as news to current and future defense spending growth.

In the second step, we use unstructured VARs to obtain empirical measures of the news variables. In the third step, we utilize the constructed news variables to estimate the fiscal adjustment betas that describe the response of expected surpluses and of expected returns to fiscal shocks. The budget constraint decomposition maps these fiscal adjustment betas directly into the fraction of fiscal shocks financed through the surplus and debt valuation channels. Our estimate of the fiscal adjustment beta for the surplus channel is 2.80, implying that a one-percent shock to defense spending growth induces, on average, a 2.80 percentage point unexpected increase in current and future non-defense surplus growth. It implies that the surplus channel has absorbed a significant portion, more than $73 \%$, of fiscal shocks in the postwar era. Our estimate for the fiscal adjustment beta for the debt valuation channel is -0.37 , which implies that innovations to real returns on government debt decrease by 37 basis points when innovations to defense spending growth increases by one percent. This translates into $9.6 \%$ of fiscal risk absorbed through the debt valuation channel. These results indicate that the U.S. government has achieved a limited, but non-negligible degree of fiscal insurance through the bond markets since 1946.

The debt valuation channel has two components: (i) return variations that are contemporaneous with fiscal news and the focus of much of the normative literature on fiscal policy, and (ii) variations in future returns following fiscal news. We find that only $1.8 \%$, about $20 \%$ of the fiscal adjustment through the debt valuation channel, is achieved through variation in current returns. Variations in future bonds returns, on the other hand, have absorbed about $7.8 \%$ of the fiscal risk in the postwar era. This latter result does not have an analogue in the normative literature where the focus is on the contemporaneous returns, but it is a robust 
feature of the data.

Our empirical results also have implications for active management of government debt. The debt valuation channel estimates reflect the response of value weighted returns on the government debt portfolio to fiscal shocks. This leads to the question whether debt of each maturity is equally effective at delivering fiscal insurance. The second contribution of our paper is to provide empirical evidence that long-term debt is a better instrument for absorbing fiscal risk. ${ }^{4}$ More specifically, the fraction of fiscal risk absorbed by debt of 1-year maturity is about $8 \%$, whereas this fraction is more than double of that amount at $18 \%$ for debt of 20-year maturity. The actual value weighted maturity of government debt in the postwar period is 3.1 years, delivering an overall fiscal insurance of $9.6 \%$ as previously stated. Our results indicate that if the response of the term structure to expenditure shocks is taken as given, the Treasury can use the bond markets more effectively to finance any unanticipated spending by lengthening the maturity of its debt portfolio.

The robustness of our fiscal adjustment results relies on the precision of our fiscal shock estimates. There is potentially an important caveat associated with using aggregate spending data to estimate these shocks, as documented by Ramey (2009). It is the possible failure of aggregate data to respond to defense spending surprises in a timely manner. Our third contribution is a VAR specification that addresses this issue. Specifically, we include information embedded in the stock returns of companies in the defense industry as additional explanatory variables. Our logic is straightforward. In so far as defense companies' profits and dividends are tied to defense spending, defense stock return variables should respond contemporaneously to news about future defense spending growth. The results from the augmented VAR confirm our intuition: defense spending growth is indeed predicted more

\footnotetext{
${ }^{4}$ In the normative fiscal literature, two papers display the use of long-term debt to absorb fiscal shocks. One is Lustig, Sleet, and Yeltekin (2008), who show that the long-term debt helps the government smooth distortions from costly unanticipated inflation in a dynamic model of optimal fiscal and monetary policy with nominal rigidities, and nominal non-contingent debt of various maturities. The other is Angeletos (2002), who argues that if the maturity structure of public debt is carefully chosen ex ante, the ex post variation in the market value of outstanding long-term debt may offset the contemporaneous variation in the level of fiscal expenditures.
} 
precisely. Reassuringly, the estimate for fiscal risk absorbed by the debt valuation channel remains above $9.5 \%$.

The paper proceeds as follows. Section 2 log-linearizes and decomposes the budget constraint, and formally defines fiscal shocks and our fiscal adjustment channels. Section 3 presents our benchmark VAR model and reports the empirical results from this benchmark case. Section 4 discusses the link between the maturity composition and degree of fiscal insurance. Section 5 introduces the VAR model augmented with defense stock variables and reports the associated results. Section 6 concludes.

\section{Government Budget Constraint and Fiscal Adjustment}

In this section we explore the implications of the government's intertemporal budget constraint and identify the fiscal adjustment channels that help finance expenditure shocks. The dynamic period-by-period version of the government's budget constraint is given by:

$$
B_{t+1}=R_{t+1}^{b}\left(B_{t}-S_{t}\right)
$$

where $B_{t}$ denotes the time- $t$ real market value of government debt outstanding at the beginning of the period. $S_{t}$ denotes the federal government's real primary surplus. It is equal

to receipts $T_{t}$, inclusive of seignorage revenue, less expenditures $G_{t} \cdot R_{t+1}^{b}$ denotes the gross real return paid on the government's bond portfolio between $t$ and $t+1$. This equation can be re-arranged to yield the following expression for the growth rate of government debt as a function of the return on this debt and the primary surplus to debt ratio:

$$
\frac{B_{t+1}}{B_{t}}=R_{t+1}^{b}\left(1-\frac{S_{t}}{B_{t}}\right) .
$$

Our goal is to measure the impact of news about current and future spending on the budget constraint. In other words, to what extent is this impact offset by contemporaneous and subsequent declines in the market value of outstanding debt and increases in future primary surpluses? To accomplish this task, we first separate the various components of the 
budget constraint by log-linearizing Equation (1). The log-linearization of the government's budget constraint follows a similar procedure to the log-linearization of the household budget constraint in Campbell (1993) and the country external budget constraint of Gourinchas and Rey (2007). Campbell's focus is asset pricing, whereas Gourinchas and Rey's is international adjustment to large trade or asset imbalances. Our main focus on the other hand is on the channels that stabilize the U.S. fiscal balance following expenditure shocks.

\subsection{Log-linearizing the budget constraint}

Campbell's linearization of the household budget constraint treats labor income as the return on human capital and, hence, part of the return on the household's overall portfolio. The constraint is then re-expressed as a function of household wealth (inclusive of human capital) and consumption, both of which are taken to be positive. In contrast, we treat government income from taxation as a part of the surplus flow rather than as a return on a government asset. The fact that the surplus may be either positive or negative creates difficulties for the log-linearization of (1). We circumvent these issues by expanding around both the average log receipts to debt and log spending to debt ratios and then constructing a weighted log primary surplus.

The log-linearization procedure is valid under the following assumptions regarding spending, receipt and surplus to debt ratios. First, we assume that for all $t$, the market value of outstanding government debt, $B_{t}$, is positive and larger than the primary surplus, $S_{t}$. Second, we assume that the logarithm of the receipts to debt ratio, $\log \left(T_{t} / B_{t}\right)$, and the $\operatorname{logarithm}$ of the spending to debt ratio, $\log \left(G_{t} / B_{t}\right)$, are stationary around their average values $\overline{\tau b}$ and $\overline{g b}$, respectively. Lastly, we suppose that $\exp (\overline{\tau b})-\exp (\overline{g b})$ lies between 0 and 1.

We have verified that our assumptions are supported by the data for our sample period of 1946.I to 2008.III. Figure 1 displays the time series of $\log \left(T_{t} / B_{t}\right)$ and $\log \left(G_{t} / B_{t}\right){ }^{5}{ }^{5}$ Optimizing the Bayesian Information Criterion proposed by Schwarz (1978), we find an optimal lag length of one for both time series. ${ }^{6}$ The associated Augmented Dickey-Fuller test statistics

\footnotetext{
${ }^{5}$ Details of the fiscal data used to construct $T$ and $G$ can be found in the appendix.

${ }^{6}$ The Akaike Information Criterion (AIC), based on Akaike (1974), penalizes the number of parameters
} 
reveal that the unit-root hypothesis can be rejected for both $\log \left(T_{t} / B_{t}\right)$ and for $\log \left(G_{t} / B_{t}\right)$ at the $5 \%$ level. $^{7}$

[Figure 1 about here.]

Throughout, our notational convention is to use lower cases to denote log variables and $\Delta$ to denote a difference, so that $b_{t}=\log B_{t}, \Delta b_{t+1}=\log B_{t+1}-\log B_{t}$, and so on. Let $n s_{t}$ denote the weighted log primary surplus:

$$
n s_{t}=\mu_{\tau} \tau_{t}-\mu_{g} g_{t}
$$

The weights are derived from the log-linearization of Equation (1) detailed in Appendix A, and are given by

$$
\mu_{\tau}=\frac{\mu_{\tau b}}{\mu_{\tau b}-\mu_{g b}} \quad \text { and } \quad \mu_{g}=\frac{\mu_{g b}}{\mu_{\tau b}-\mu_{g b}}
$$

where $\mu_{\tau b}=\exp (\overline{\tau b})$ and $\mu_{g b}=\exp (\overline{g b})$. In Appendix A, we also show that under the above assumptions, and ignoring unimportant constants, the log-linearization yields the following approximation for the law of motion for debt:

$$
\Delta b_{t+1}=r_{t+1}^{b}+\left(1-\frac{1}{\rho}\right)\left(n s_{t}-b_{t}\right)
$$

where $\mu_{s b}=\mu_{\tau b}-\mu_{g b}$ and $\rho=\left(1-\mu_{s b}\right) \in(0,1)$.

Equation (4) implies the first-order difference equation:

$$
n s_{t}-b_{t}=\rho r_{t+1}^{b}-\rho \Delta n s_{t+1}+\rho\left(n s_{t+1}-b_{t+1}\right)
$$

Solving (5) forward and imposing the tail condition $\lim _{j \rightarrow \infty} E_{t} \rho^{j}\left(n s_{t+j}-b_{t+j}\right)=0$, we obtain

less severely and as a result suggests that including two $\left(\log \left(T_{t} / B_{t}\right)\right)$ or five $\left(\log \left(G_{t} / B_{t}\right)\right)$ lags is optimal. In any case, the AIC test statistics were fairly flat for one to ten lags, for both time series.

${ }^{7}$ The $\mathrm{ADF}(0)$ test statistic is -3.0879 for $\log \left(T_{t} / B_{t}\right)$ and -3.1182 for $\log \left(G_{t} / B_{t}\right)$, each with a $5 \%$ critical value of -2.8418. See Said and Dickey (1984) for details. 
the following expression for the weighted log surplus to debt ratio, $n s_{t}-b_{t}$ :

$$
n s_{t}-b_{t}=E_{t} \sum_{j=1}^{\infty} \rho^{j}\left(r_{t+j}^{b}-\Delta n s_{t+j}\right)
$$

The expression in (6) implies that if the log surplus to debt ratio fluctuates, it has to be due to either a change in expected future returns on outstanding debt, or a change in expected surplus growth. The log surplus to debt ratio reveals deviations from the long-run relationship between surpluses and debt. If it is negative, the surplus is small relative to the market value of debt. In this case, we expect low future returns on government debt or high future surplus growth. If the log surplus to debt ratio is positive, we anticipate high future returns on debt or low future surplus growth.

We now re-express Equation (6) in terms of innovations. Computing the difference between expectations at time $t+1$ in (6) minus those at time $t$, and moving $b_{t+1}-E_{t} b_{t+1}=$ $r_{t+1}^{b}-E_{t} r_{t+1}^{b}$ to the right-hand side, yields the following expression:

$$
n s_{t+1}-E_{t} n s_{t+1}=\left(E_{t+1}-E_{t}\right) \sum_{j=0}^{\infty} \rho^{j} r_{t+j+1}^{b}-\left(E_{t+1}-E_{t}\right) \sum_{j=1}^{\infty} \rho^{j} \Delta n s_{t+j+1} .
$$

Since $n s_{t+1}-E_{t} n s_{t+1}=\left(E_{t+1}-E_{t}\right) \Delta n s_{t+1}$, we have:

$$
\left(E_{t+1}-E_{t}\right) \Delta n s_{t+1}=\left(E_{t+1}-E_{t}\right) \sum_{j=0}^{\infty} \rho^{j} r_{t+j+1}^{b}-\left(E_{t+1}-E_{t}\right) \sum_{j=1}^{\infty} \rho^{j} \Delta n s_{t+j+1}
$$

In what follows, we refer to $\left(E_{t+1}-E_{t}\right) X_{t+1}$ as innovations, news, shocks to $X_{t+1}$ for any process $X$. Equation (7) then states that a positive shock to the (weighted log) surplus growth must correspond either to a positive shock to returns on government debt or to a negative shock to surplus growth. As a corollary, we can infer news about surplus growth from news about returns on government debt.

Ultimately, we are interested in finding out how much the government uses each of the two channels, lower bond returns or higher future surpluses, to finance its unanticipated 
spending needs. Therefore, we decompose Equation (7) further to isolate the component of the government's budget that we identify with expenditure shocks.

\subsection{Fiscal Shocks and Fiscal Adjustment Channels}

The presence of active fiscal policy and its associated implementation lags complicate the timing and extraction of news to government expenditures from aggregate government spending data. Ramey (2009) advocates using defense spending data to identify fiscal shocks. She argues that fluctuations in defense spending account for almost all of the fluctuations in total government spending relative to its trend and that non-defense spending accounts for most of the trend in government spending. Ramey also shows evidence that suggests most non-defense spending is done by state and local governments rather than the federal government, undermining the ability of empirical estimations relying on aggregate expenditure data to capture unanticipated changes to government spending.

Following Ramey, we define exogenous shocks to government spending, i.e. fiscal shocks, as innovations to defense spending growth. We do not argue that all defense spending is exogenous, but rather that innovations to defense spending are a measure of shocks to government expenditures. To identify these fiscal shocks, we first separate government spending into defense and non-defense components. We then re-derive the log-linearization of the budget constraint in Appendix A by expanding $\log \left(1+\frac{S_{t}}{B_{t}}\right)$ in (A.2) around three components: the average log receipt to debt ratio, $\overline{\tau b}$, the average log non-defense spending to debt ratio, $\overline{g b}^{\text {ndef }}$, and the average log defense to debt ratio, $\overline{g b}^{\text {def }}$. We can then redefine $n s_{t}$ as:

$$
n s_{t}=\mu_{\tau} \tau_{t}-\mu_{g}^{n d e f} g_{t}^{n d e f}-\mu_{g}^{\text {def }} g_{t}^{\text {def }}
$$

where $\mu_{\tau}$ is defined as before, and

$$
\mu_{g}^{n d e f}=\frac{\mu_{g b}^{n d e f}}{\mu_{\tau b}-\mu_{g b}^{n d e f}-\mu_{g b}^{d e f}} \quad \text { and } \quad \mu_{g}^{d e f}=\frac{\mu_{g b}^{d e f}}{\mu_{\tau b}-\mu_{g b}^{n d e f}-\mu_{g b}^{d e f}}
$$

with $\mu_{g b}^{n d e f}=\exp \left(\overline{g b}^{n d e f}\right)$ and $\mu_{g b}^{d e f}=\exp \left(\overline{g b}^{\text {def }}\right)$. We denote the weighted log surplus 
excluding defense spending with $n s_{t}^{\text {ndef }}=\mu_{\tau} \tau_{t}-\mu_{g}^{\text {ndef }} g_{t}^{\text {ndef }}$. This implies that:

$$
\Delta n s_{t+1}=\Delta n s_{t+1}^{n d e f}-\mu_{g}^{d e f} \Delta g_{t+1}^{d e f}
$$

where $\Delta g_{t+1}^{\text {def }}$ denotes the growth in defense spending. Substituting the last equation into (7), and rearranging produces the following relation between news about defense spending growth, news about government debt returns and news about non-defense surplus growth:

$$
\begin{aligned}
\left(E_{t+1}-E_{t}\right) \sum_{j=0}^{\infty} \rho^{j} \Delta g_{t+j+1}^{\text {def }}= & -\frac{1}{\mu_{g}^{d e f}}\left(\left(E_{t+1}-E_{t}\right) \sum_{j=0}^{\infty} \rho^{j} r_{t+j+1}^{b}\right) \\
& +\frac{1}{\mu_{g}^{d e f}}\left(\left(E_{t+1}-E_{t}\right) \sum_{j=0}^{\infty} \rho^{j} \Delta n s_{t+j+1}^{n d e f}\right)
\end{aligned}
$$

where $\rho$ is now computed as $1-\left(\mu_{\tau b}-\mu_{g b}^{\text {ndef }}-\mu_{g b}^{\text {def }}\right)$.

Equation (10) is central to our analysis and guides our empirical strategy. It identifies two main channels for stabilizing the government's fiscal balances following an expenditure shock. It implies that a positive shock to defense expenditure growth has to coincide with one of two things: a negative shock to returns on debt, and/or a positive shock to non-defense surplus growth. We refer to the first of these adjustments as the debt valuation channel, and the second as the surplus channel. To quantify the relative importance of each of these channels, we first develop a framework to construct these news variables and then measure the empirical relationship between them.

The normative fiscal theory refers to the debt valuation channel, specifically the current return component of the debt valuation channel, as fiscal insurance. Standard models in the normative literature feature a benevolent government that minimizes the welfare losses arising from variation in marginal tax rates over time and states. If the tax system is sufficiently constrained, then the government will wish to smooth inter-state marginal tax rates and the excess burden of taxation by varying the return it pays on its debt. ${ }^{8}$ The

\footnotetext{
${ }^{8}$ If the government has access to lump sum taxation, then Ricardian Equivalence implies that it need
} 
extent to which it can do this is determined by the asset market structure it faces.

In complete market models, there are no restrictions on the government's ability to insure against shocks through return variations. ${ }^{9}$ At the other extreme, if the government can trade only one period real non-contingent debt, then optimal policy entails intertemporal rather than interstate smoothing of taxes and the excess burden. ${ }^{10}$ Intermediate cases in which fiscal insurance is possible, but costly, deliver intermediate results. In these scenarios, the government optimally responds to shocks with a mixture of interstate and intertemporal smoothing of taxes and the excess burden. ${ }^{11}$

Several contributors, beginning with Barro (1979), have used normative models of the sort described above to assess fiscal policy empirically. Early analysis found evidence of persistence in tax rates consistent with incomplete-market models. ${ }^{12}$ More recent work by Scott (2007) and Marcet and Scott (2009) has obtained and empirically assessed the implications of complete and incomplete markets optimal policy models. These two papers provide further evidence of persistence in debt levels and tax rates relative to allocations, suggestive of incomplete-market models and hence limited access to fiscal insurance through bond markets. We, on the other hand, do not take any ex-ante stance on the degree of market completeness or on the preferences of the government. That is, we do not distinguish between the government's inability or unwillingness to engage in fiscal insurance. Our framework relies only on

make no recourse to bond markets. If it can tax private assets without inducing any contemporaneous distortion, then asset taxation can substitute for variations in debt returns. Lastly, if the government can flexibly adjust both consumption and income tax rates in response to shocks, then again debt is redundant as a fiscal insurance mechanism (see Correia, Nicolini, and Teles (2008)). On the other hand, if the tax system is sticky or if the government is constrained to adjust income tax rates in the aftermath of shocks, then debt's essential role as a fiscal insurance instrument is reinstated.

${ }^{9}$ Scott (2007) shows that when markets are complete, the government maintains the excess burden of taxation - the shadow value of the future primary surplus stream - at a constant level. Labor tax rates still vary to the extent that the compensated labor supply elasticity varies. However, these variations are typically dampened relative to an incomplete-market setting.

${ }^{10}$ See Barro (1979) and Aiyagari, Marcet, Sargent, and Seppala (2002).

${ }^{11}$ One example is Lustig et al. (2008). There, a government trades nominal non-contingent debt of various maturities. Costly contemporaneous or expected future inflations allow it to hedge fiscal shocks. Another example is Sleet (2004) who requires fiscal policy to satisfy incentive compatibility restrictions.

${ }^{12}$ See, for example, Sahasakul (1986), Bizer and Durlauf (1990) and Hess (1993). However, as Bohn (1998) and Scott (2007) point out, the unit root tests used in this literature have low power against the alternative of optimal policy in an environment with complete markets and persistent shocks. 
the intertemporal budget constraint of the government, which is consistent with all dynamic fiscal models. Our goal is to develop a method for quantifying fiscal adjustments, and apply this method to postwar U.S. data. More specific theoretical mechanisms can be introduced into our framework and tested as restrictions. However, they will have to be consistent with the two channels of adjustment and their relative quantitative importance. Our findings can provide useful information to guide the theoretical fiscal management literature.

We now describe how we use Equation (10) to quantify the debt valuation and surplus adjustments to fiscal shocks.

\subsection{Quantifying fiscal adjustments}

The debt valuation channel operates through a decline in contemporaneous and expected future returns on the government's debt portfolio when news about higher defense spending growth is revealed, whereas the surplus channel operates through an increase in contemporaneous and expected future non-defense surplus growth. When the government is fully insured against spending shocks, the negative shock to expected returns completely offsets the surprise increase in expected defense spending growth. If fiscal shocks are not financed through the debt valuation channel fully, then the government will have to run larger surpluses now or in the future. Before we quantify the relative importance of these two channels, we introduce the following pieces of notation. We denote news about current and future defense spending growth by

$$
h_{t+1}\left(g^{d e f}\right)=\left(E_{t+1}-E_{t}\right) \sum_{j=0}^{\infty} \rho^{j} \Delta g_{t+j+1}^{d e f},
$$

news about current and future returns on government debt by

$$
h_{t+1}\left(r^{b}\right)=\left(E_{t+1}-E_{t}\right) \sum_{j=0}^{\infty} \rho^{j} r_{t+j+1}^{b}
$$

and news about current and future non-defense surplus growth by

$$
h_{t+1}\left(n s^{n d e f}\right)=\left(E_{t+1}-E_{t}\right) \sum_{j=0}^{\infty} \rho^{j} \Delta n s_{t+j+1}^{n d e f} .
$$


With these pieces of notation in place, we can also formally define fiscal insurance in our framework to be a negative covariance between innovations to current and future defense spending growth and innovations to current and future returns:

$$
\operatorname{cov}\left(h_{t+1}\left(g^{\text {def }}\right), h_{t+1}\left(r^{b}\right)\right)<0 .
$$

To assess how much of the spending shocks is absorbed by debt returns and by future surpluses, we regress both the news about returns and the news about surplus growth on innovations to defense spending growth separately:

$$
\begin{aligned}
h_{t+1}\left(r^{b}\right) & =\beta_{0}^{r}+\beta_{1}^{r} h_{t+1}\left(g^{\text {def }}\right)+\varepsilon_{t+1}^{r}, \\
h_{t+1}\left(n s^{n d e f}\right) & =\beta_{0}^{n s}+\beta_{1}^{n s} h_{t+1}\left(g^{d e f}\right)+\varepsilon_{t+1}^{n s} .
\end{aligned}
$$

If $\beta_{1}^{r}$ is equal to minus one, the total decline in innovations to current and future debt returns is one percent when the innovations to current and future defense expenditure growth rises by one percent. According to Equation (10), we can map this beta directly into a fraction of total fiscal risk financed by the debt valuation channel. If $\frac{1}{\mu_{g}^{d e f}} \beta_{1}^{r}$ is minus one, the government is obviously fully fiscally insured and does not require any adjustment through the surplus channel. Analogously, if $\frac{1}{\mu_{g}^{d e f}} \beta_{1}^{\text {ns }}$ is one, the surplus channel fully absorbs the fiscal shocks.

\section{Benchmark VAR Results}

This section presents our estimation results. We start by setting up a benchmark VAR model to construct innovations to defense spending growth, to government debt returns and to non-defense surplus growth. These news variables are then used to estimate the fraction of fiscal shocks financed by each adjustment channel. 


\subsection{Estimating the News Variables}

We use unrestricted VARs to forecast future government debt returns, defense spending and non-defense surplus growth, and construct estimates of their innovations from the forecasts. Our sample consists of quarterly data and covers the postwar years from 1946 to 2008. The state vector, $z_{t}$, includes variables that help estimate the terms in Equation (10). We make the assumption that there are no relevant innovations to slow-moving trends for any of the three variables in Equation (10). This allows us to remove the slow-moving trend components of debt returns, defense spending growth and non-defense surplus growth in order to estimate their innovations more precisely. If there are, however, any sudden changes to trends, then the detrended time series would not capture these innovations and affect the precision of our findings. Therefore we exercise great caution by providing a number of robustness checks on our detrending procedure when we present the results. We now explain the construction of the news variables, their relevant data sources and our detrending procedure.

Real holding returns on government debt, $r_{t}^{b}$, are constructed in several steps. Using CRSP Treasury bill and coupon-bond price data, we first employ the Nelson and Siegel (1987) technique to extract the time- $t$ nominal zero-coupon yield curve. ${ }^{13}$ This enables us to compute nominal discount rates, which are converted to real terms using the Consumer Price Index (CPI). Let $P_{t}^{k}$ denote the real price of a synthetic zero-coupon government bond that matures at time $t+k$, for $k=1, \ldots, 120$, where $k$ represents quarters. The time- $t$ real holding return on government debt maturing at $t+k$ can then be computed as $r_{t}^{k}=\frac{P_{t}^{k-1}-P_{t-1}^{k}}{P_{t-1}^{k}}$. We obtain $r_{t}^{b}$ by forming the value-weighted average of the quarterly real holding returns $r_{t}^{k}$, across all maturities $k$ :

$$
r_{t}^{b}=\sum_{k=1}^{120} w_{t-1}^{k} r_{t}^{k}
$$

\footnotetext{
${ }^{13}$ To facilitate the yield-curve extraction, we clean the price data so that it contains only straight bonds with a maturity of at least one year plus T-bills with 30-days or longer until maturity. We also remove all bonds with $1.5 \%$ coupon rates, as they have been documented to contain large spurious errors. For details, see pg. 27 of the CRSP Monthly Treasury U.S. Database Guide.
} 
where $w_{t-1}^{k}$ is the weight for maturity $k$ measured at time $t-1$. It is defined as:

$$
w_{t-1}^{k}=\frac{s_{t-1}^{k} P_{t-1}^{k}}{\sum_{l=1}^{120} s_{t-1}^{l} P_{t-1}^{l}} .
$$

In the above equation $s_{t}^{k}$ denotes the number of time- $(t+k)$ dollars the government has promised to deliver as of time $t$. The series $s_{t}^{k}$ is determined from the CRSP Monthly Treasury database going back to 1960 and from the Treasury Bulletins, the Wall Street Journal and the New York Times for the years 1946 to 1960. These files contain monthly data on the maturity and face value of outstanding publicly held debt, plus coupon-rate data on virtually all negotiable direct obligations of the U.S. Treasury. We unbundle each outstanding bond at time $t$ into its principal and coupon payments, and then construct $s_{t}^{k}$ by accumulating, across all bonds, the notional amounts due in $k$ periods. ${ }^{14} \mathrm{~A}$ similar accounting technique is used in Hall and Sargent (1997) for computing the government's real cost of borrowing. ${ }^{15}$ Figure 2 shows the times series of $r_{t}^{b}$ for our sample period of 1946.I to 2008.III. The average return is close to zero at $0.34 \%$, but the series displays considerable variation with a standard deviation of $2.34 \%$.

[Figure 2 about here.]

We do not find any significant trend component in government debt returns. We do, however, observe a sudden upward shift in the average level of returns around $1981 .^{16}$ We do not view this increase as part of a slow moving trend but rather as an innovation to government debt returns, which we would like to capture. It is possible that this shift in the average returns is related to Volcker disinflation starting in the early 1980's. We therefore

\footnotetext{
${ }^{14}$ Note that CRSP does not report the face value of Treasury bills held by the public, and that these data are obtained from table FD-5 of the monthly Treasury Bulletins.

${ }^{15}$ The Treasury reports the interest cost of total government debt, calculated by summing up all the principal and coupon payments the government has promised to deliver at $t+k$ as of time $t$. The Treasury's methodology makes no distinction between coupon payments and principal payments, and hence mismeasures the cost of funds.

${ }^{16}$ Between 1946 and 1980, real holding returns $r_{t}^{b}$ fluctuate around zero, but starting in 1981, the average return level increases to $1.2 \%$.
} 
include inflation as a state variable in our VAR analysis, but do not detrend $r_{t}^{b}$.

To construct $n s_{t}^{\text {ndef }}$, we first compute $\mu_{\tau}, \mu_{g}^{\text {ndef }}$ and $\mu_{g}^{\text {def }}$ from the sample averages of the log receipts to debt, log non-defense spending to debt and log defense spending to debt ratios. For our sample period of 1946.I to 2008.III, these weights are $\mu_{\tau}=10.877$, $\mu_{g}^{n d e f}=6.064$ and $\mu_{g}^{\text {def }}=3.813$. Receipts include current federal tax revenues, contributions for social insurance, income receipts on other assets, current transfer receipts and seignorage revenue. Non-defense spending includes all federal expenditures excluding national defense spending, $g^{\text {def }}$, and excluding interest on debt. Most data are obtained from NIPA tables. The monetary base for calculating the seignorage revenue is obtained from the St. Louis FRED. The computation of the seignorage revenue and the details of the fiscal data are explained further in Appendix B. The debt in question is $B_{t}$ calculated as:

$$
B_{t}=\sum_{k=1}^{120} s_{t-1}^{k} P_{t}^{k-1} .
$$

Therefore $B_{t}$ measures the time- $t$ real market value of bonds outstanding at the end of $t-1 /$ beginning of $t$.

We detrend $\Delta g_{t}^{\text {def }}$ and $\Delta n s_{t}^{\text {ndef }}$ using a one-sided Hodrick and Prescott (1997) (HP) filter. The one-sided HP filter uses only past values to estimate the trend and hence preserves the temporal ordering of data. In detrending the two series, we use a smoothing factor of 8330, which tends to cut out frequencies corresponding to periods above 15 years. We choose 15 years as our benchmark because that is the average time between consecutive increases in defense spending, as documented by Ramey (2009) and displayed in Figure 3. The figure includes real defense spending and the Ramey dates for our sample period. The latter are (1941.I,) 1950.III, 1965.I, 1980.I, and 2001.III. For completeness, we do provide results from a variety of cycles, including the standard cycle length of 9.9 years, employed by the business cycle literature.

[Figure 3 about here.]

The state vector $z_{t}$ for the benchmark VAR also includes two additional variables known 
to predict real bond returns: quarterly inflation, $\pi_{t}$, computed as the quarterly rate of change of the CPI and the quarterly Cochrane and Piazzesi (2005) risk factor, $C P_{t}$. This leaves us with a five-dimensional state vector:

$$
z_{t}=\left(\begin{array}{lllll}
r_{t}^{b} & \pi_{t} & \xi_{t}^{n s, n d e f} & C P_{t} & \xi_{t}^{g, d e f}
\end{array}\right)
$$

where $\xi_{t}^{n s, n d e f}$ and $\xi_{t}^{g, n d e f}$ are the detrended $\Delta n s^{\text {ndef }}$ and $\Delta g^{\text {def }}$ series, respectively. All variables, except inflation and $C P$, are deflated using the CPI. We demean all the variables and impose a first-order structure on the VAR:

$$
z_{t+1}=A z_{t}+\varepsilon_{t+1}
$$

Table 1 reports the GMM estimates with their t-statistics. Our results show that this simple specification does reasonably well in predicting the returns on government debt. The $R^{2}$ on the return equation is $13.5 \%$, with significant coefficients for $C P$ and inflation. Our results also indicate that, as one would expect, none of the variables are significant in predicting the non-defense surplus growth or in predicting defense spending growth.

\section{[Table 1 about here.]}

We calculate the news about current and future defense spending growth from the benchmark VAR estimates as:

$$
h_{t+1}\left(g^{d e f}\right)=e_{5}(I-\rho A)^{-1} \varepsilon_{t+1},
$$

where $e_{i}$ represents a row vector of dimension five, with one in the i'th position and zero everywhere else and $\varepsilon_{t+1}$ represent the VAR residuals. We set $\rho=1-\left(\mu_{\tau b}-\mu_{g b}^{\text {ndef }}-\mu_{g b}^{\text {def }}\right)$ equal to its postwar sample value of 0.9855 . We obtain news about current and future government debt returns via:

$$
h_{t+1}\left(r^{b}\right)=e_{1}(I-\rho A)^{-1} \varepsilon_{t+1} .
$$


In a similar fashion, we also compute innovations to current and future non-defense surplus growth as follows:

$$
h_{t+1}\left(n s^{\text {ndef }}\right)=e_{3}(I-\rho A)^{-1} \varepsilon_{t+1} .
$$

\subsection{Fiscal Adjustment Results}

We now report our empirical fiscal adjustment results and implement a number of robustness checks.

\subsubsection{Empirical correlations}

Table 2 reports the correlations between the news variables on its off diagonals, whereas the diagonals contain the standard deviations of these variables. We make the following observations. First, news about current and future defense spending growth are strongly negatively correlated with news about current and future returns on government debt (-0.72), providing strong evidence of fiscal insurance in the postwar period. Second, innovations to current and future defense spending growth have twice the volatility of government debt returns. Third, innovations to current and future defense spending growth are positively correlated with innovations to non-defense surplus growth, providing evidence for fiscal adjustment through the surplus channel. The news to non-defense surplus growth is very volatile, with a standard deviation roughly seven times that of news to defense spending growth and 15 times that of news to government debt returns. Finally, there is a moderate negative correlation $(-0.42)$ between news to debt returns and news to non-defense surplus growth, indicating that the interaction between the surplus and the debt valuation channels increases the total amount of fiscal shocks absorbed, rather than counteracting either of the channels.

[Table 2 about here.]

\subsubsection{Fiscal Adjustment Betas}

Table 3 reports the betas from the fiscal adjustment regressions and maps these betas into the fraction of fiscal shocks absorbed by the debt valuation and surplus channels. The 
fiscal adjustment beta for the debt valuation channel (Line 3) is -0.37, implying that a onepercent shock to defense spending growth induces, on average, a 37 basis points unexpected drop in returns on outstanding public debt. This implies that a sizable degree of government spending risk was born by bond holders in the postwar era: $9.61 \%$ of expenditure shocks were absorbed by an unanticipated decline in current and future bond returns. Over this period, innovations to current and future defense spending growth have accounted for $52 \%$ of the total variation in innovations to current and future holding returns on the federal government's outstanding portfolio of bonds.

[Table 3 about here.]

The fiscal adjustment beta for the surplus channel (Line 4) is 2.80, implying that a one-percent shock to defense spending growth induces, on average, a 2.80 percentage point unexpected increase in current and future non-defense surplus growth. It implies that the surplus channel has absorbed a significant portion, 73.34\%, of fiscal shocks in the postwar era. Over this period, innovations to current and future defense spending growth have accounted for $16 \%$ of the total variation in innovations to current and future surplus growth. These results imply that over the sample period, adjustments in bond returns and non-defense surpluses together have financed about $83 \%$ of fiscal shocks.

Table 3 also reports fiscal adjustment betas for two components of the debt valuation channel: adjustments to current returns and adjustments to future returns. The current fiscal adjustment beta is obtained by regressing the first term in $h_{t+1}\left(r^{b}\right)$, which is $h_{t+1}^{c}\left(r^{b}\right)=$ $\left(E_{t+1}-E_{t}\right) r_{t+1}^{b}$, on $h_{t+1}\left(g^{\text {def }}\right)$. According to our estimates, this beta, although statistically significant, is only -0.069. It implies that between 1946 and 2008, only $1.81 \%$ of spending shocks were absorbed by a surprise decline in contemporaneous debt returns. Most of the adjustment to debt returns after a fiscal shock has come in the form of a decline in future debt returns. The future fiscal adjustment beta, obtained by regressing $h_{t+1}^{f}\left(r^{b}\right)=\left(E_{t+1}-\right.$ $\left.E_{t}\right) \sum_{j=1}^{\infty} \rho^{j} r_{t+j+1}^{b}$, on $h_{t+1}\left(g^{\text {def }}\right)$, is -0.30 , which corresponds to $7.80 \%$ of the fiscal shocks financed. The normative literature on fiscal policy emphasizes the role of contemporaneous 
adjustment to returns in providing fiscal insurance. Our results show that adjustments to future returns play an important role and help absorb more of the expenditure shocks. This suggests an additional fiscal adjustment channel for normative models to explore.

\subsubsection{Robustness Checks}

The fiscal adjustment estimates reported in Table 3 are sensitive to the smoothing parameter we use in our HP filter. Our benchmark smoothing factor is 8330, corresponding to 15-year cycles. In Table 4 we report fiscal adjustment betas and the fraction of expenditure risk absorbed by the debt valuation and surplus channels for a variety of smoothing parameters corresponding to shorter and longer cycles. Our findings suggest that as the cycle length increases, three things happen. First, the fraction of fiscal shocks financed by the debt valuation channel decreases, while the opposite is true for the surplus channel. Second, the fiscal adjustment betas are more precisely estimated. Third, the total expenditure risk absorbed by the two channels increases. ${ }^{17}$ The results also indicate that regardless of the cycle length, the U.S. government has achieved some degree of fiscal insurance through the bond markets during the postwar era.

[Table 4 about here.]

\section{Debt Maturity and Fiscal Insurance}

The previous section documented that in the postwar era, the U.S. government financed part of its surprise spending needs through the bond markets. The normative fiscal theory proposes two ways to deliver fiscal insurance in the absence of real state-contingent debt. One is through surprise increases in inflation in the presence of nominal non-contingent debt (e.g., Bohn (1988)), the other is by a careful choice of the maturity structure when only real non-contingent debt is available (e.g., Angeletos (2002)). The latter suggests that the

\footnotetext{
${ }^{17}$ The sum of $\beta_{1}^{r} / \mu_{g}^{\text {def }}$ and $\beta_{1}^{n s} / \mu_{g}^{\text {def }}$ can differ from one since Equation (10) is an approximation derived from the intertemporal budget constraint, and hence need not hold with equality. We do not impose any restrictions on the size of the betas, nevertheless our empirical estimates show that their sum is reasonably close to one.
} 
composition of the government's debt portfolio plays an important role in the degree of financing through the debt valuation channel. ${ }^{18}$ In this section, we take a closer look at the composition of government debt and identify the maturities that are more effective in delivering fiscal insurance. We begin by showing some summary statistics. Table 5 displays the average quarterly real holding return and its standard deviation for bonds of different maturities.

[Table 5 about here.]

Table 5 shows that real holding returns on long-term debt are significantly more volatile than returns on short-term debt. The higher volatility of returns to long-term debt has led to arguments for shortening the maturity structure, both in the normative tax literature and in other related work. Campbell (1995) argues that a cost-minimizing government should respond to a steeply sloped nominal yield curve by shortening the maturity structure since high yield spreads tend to predict high expected bond returns in the future. Barro (1997) emphasizes tax smoothing considerations. He argues that governments can reduce their risk exposure and better smooth taxes by shortening the maturity structure when the inflation process becomes more volatile and persistent.

To quantitatively assess the effectiveness of different maturities of debt in financing fiscal shocks, we modify our benchmark VAR to include the real holding returns on zero-coupon bonds of $k$-year maturity, $r_{t}^{k}$ for each $k \in\{1,5,10,15,20\}$, in addition to all the variables in the benchmark VAR. The new VAR is:

$$
z_{t+1}^{k}=A^{k} z_{t}^{k}+\varepsilon_{t+1}^{k}, \quad \text { for } k=1,5,10,15,20 .
$$

The state vector $z_{t}^{k}$ now includes six variables:

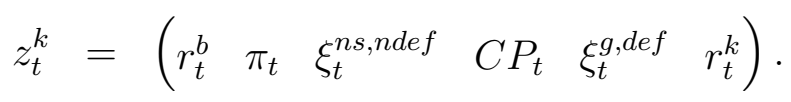

\footnotetext{
${ }^{18}$ Inflation is included in our state space for the benchmark VAR. Therefore, our fiscal insurance estimates represent adjustments to real returns after controlling for inflation.
} 
For each maturity $k$, we re-estimate Equation (13) and compute the news about current and future government returns, $h_{t+1}\left(r^{k}\right)$, by:

$$
h_{t+1}\left(r^{k}\right)=e_{6}\left(I-\rho A^{k}\right)^{-1} \varepsilon_{t+1}^{k} .
$$

As before, we then regress the news variable $h_{t+1}\left(r^{k}\right)$ on innovations to current and future defense spending growth, $h_{t+1}\left(g^{\text {def }}\right)$, for each $k$. The resulting fiscal adjustment beta estimates, $\beta_{1}^{r, k}$, are reported in Table $6 .^{19}$ All of the estimated betas are significantly negative at the five percent level. The beta of government debt returns more than doubles from -0.29 for 1-year debt to -0.67 for 20-year debt. Correspondingly, the fraction of expenditure shocks financed increases from $7.68 \%$ to $17.69 \%$.

[Table 6 about here.]

The results in Table 6 show that long-term debt is more effective in absorbing fiscal shocks than short-term debt. To the best of our knowledge, this is the first empirical documentation of the role of long-term debt as an effective fiscal insurance instrument for the government. ${ }^{20}$ Our results indicate that this feature of long-term debt helps mitigate concerns raised by Campbell (1995) and Barro (1997) about the costs of using long-term debt and should be incorporated into active debt management recommendations. More specifically, we show that if the response of the term structure to defense expenditure shocks is taken as given, the government can finance more of its shocks through bond markets by lengthening the maturity of its debt portfolio. ${ }^{21}$

\footnotetext{
${ }^{19}$ The VAR estimates are not included for space considerations, but are available upon request.

${ }^{20}$ Lustig et al. (2008) analyze the structure of optimal debt management in an environment with noncontingent nominal debt of various maturities. They show that when costly contemporaneous or expected future inflations allow the government to hedge fiscal shocks, optimal debt management calls for issuing long term debt only, due to its superior performance in financing expenditure shocks.

${ }^{21}$ This exercise is more in the partial equilibrium spirit of Campbell (1995), not in the general equilibrium spirit of the optimal tax literature.
} 


\subsection{Actual maturity structure of government debt}

Table 6 shows that the fraction of fiscal adjustment provided by value weighted returns, $9.61 \%$, falls between the fraction of fiscal risk absorbed by 1-year bonds, $7.68 \%$ and 5 -year bonds, $11.04 \%$. This suggests that the value weighted maturity of US government debt over the sample period is between 1 and 5 years. Figure 4 displays the face value weighted and market value weighted maturity structure of U.S. government debt between 1939.I and 2008.III. Both maturity series fluctuate substantially at low frequencies. At the end of the WWII, the value weighted maturity was around eight years, declining to less than two years by the mid-seventies. The face-value weighted maturity shows a similar pattern, rising above 8.5 years after WWII and declining to 2.5 years in the mid-seventies. Both maturity series start to increase again in the eighties and stay close to or above three years for the value weighted and above four years for the face value weighted maturity until the end of the sample. Since we use value weighted returns to quantify the debt valuation channel, we focus on the market value weighted maturity. As anticipated, the average value of this series for our regression sample period, between 1946.I and 2008.III, is 3.1 years. This average, combined with the maturity by maturity fiscal insurance results in Table 6, is consistent with our benchmark results for the debt valuation channel. The results in Table 6 coupled with the evolution of the weighted maturity of debt indicates that the U.S. government was able to finance defense expenditure shocks in the mid-40s to early 50s, and again from the mid-80s and to the end of the sample period, more effectively using bond markets. It also suggests that any defense expenditure shock arriving in the 70s could have been possibly better insured against had the government not decreased the maturity level to below two years during this time.

[Figure 4 about here.]

In a related paper, Faraglia et al. (2008a) investigate the role of debt management in providing insurance against budget shocks. They propose a battery of tests to assess the quality of debt management in OECD countries for the sample period 1970 to 2000. They 
have two findings that are related for our results. First, the various covariance measures used suggest that the amount of fiscal insurance achieved for the U.S. through bond markets between 1970 and 2000 is limited, i.e. well below the complete markets model's implications of full insurance. Our findings confirm this, albeit for a longer sample period, and with a different methodology.

Their second result concerns the link between debt structure (maturity and indexation) and fiscal insurance. Faraglia et al. (2008a) assert that this link is weak, and because yields show little variation, complete fiscal insurance can only be achieved through extreme portfolio positions or alternative forms of contingent securities. ${ }^{22}$ We, on the other hand, are able to show empirically that increasing the value weighted maturity structure from one year to 20 years can more than double the amount of fiscal insurance. There are multiple differences between our approach and theirs, contributing to the differences in the importance of maturity of debt in absorbing expenditure risk. First, our sample period is different, as it extends back to 1946. We identify fiscal shocks as innovations to defense spending growth, whereas Faraglia, Marcet and Scott identify them as innovations to deficits. We quantify the amount of fiscal insurance by estimating fiscal adjustment betas and mapping them into the fraction of fiscal risk absorbed by current and future return variations, whereas they quantify fiscal insurance by the negative covariance between deficit shocks and the current market value of debt. Faraglia, Marcet and Scott approximate the market value of debt from average coupon and maturity numbers whereas we unbundle, price and rebundle every outstanding bond to construct this value, preserving not only the volatility of the market value of debt, but more importantly the volatility of holding returns at each maturity. We do not, however, explore the maturity structure necessary to replicate full fiscal insurance, as this is not our focus.

\footnotetext{
${ }^{22}$ In a second paper, Faraglia, Marcet, and Scott (2008b) provide numerical examples of such portfolios (see also Buera and Nicolini (2004)). They argue that the volatile, extreme positions needed to replicate complete markets allocations in an environment with non-contingent debt of various maturities are compelling reasons to abandon the complete markets approach to debt management. The authors advocate using incomplete markets models to study optimal debt management.
} 


\section{Defense Shocks and Defense Stocks}

For our measures of the debt valuation and surplus channels to be precise, it is important that we estimate innovations to defense spending growth well. These innovations represent any changes to the information set expectations are conditioned on. These changes stem from previously expected but eventually unrealized movements in defense spending growth, and/or from previously unanticipated yet realized movements in defense spending growth. Two factors potentially complicate the extraction of such forecasts from macroeconomic data. First, agents may learn about political and/or military events driving future defense spending growth in advance of this growth occurring or affecting other aggregate variables. Second, macroeconomic data may dilute the new information on defense spending growth during aggregation. Thus, VARs relying exclusively on such aggregate data may fail to identify the true date of the shock. ${ }^{23}$ We propose a new VAR specification that augments our benchmark one and addresses these issues. More specifically, we modify our benchmark VAR specification to include information embedded in the stock returns of companies in the defense industry. Our logic is straightforward. In so far as defense companies' profits and dividends are tied to defense spending, defense stock return variables should immediately capture any new information about defense spending growth. If our intuition is correct, then defense stock returns will help identify fiscal shocks more precisely.

\subsection{Defense Stocks: Excess Returns}

First, we consider augmenting the benchmark VAR with excess returns on defense stocks, $r_{t}^{\text {def }}$, relative to the market return, $r_{t}^{m}$, and their price to dividend ratios as additional forecasting variables. Defense stocks are identified as firms with SIC codes between 37603769 (Guided missiles and space vehicles), 3795-3795 (Tanks and tank components) and 3480-3489 (Ordnance \& accessories). This is identical to the Fama-French definition of the "Guns" industry in their 49 industry portfolios. ${ }^{24}$ We use CRSP cum-dividend returns for all

\footnotetext{
${ }^{23}$ See Ramey (2009) for a discussion of the causes and implications of mis-timing shocks when using the VAR approach.

${ }^{24}$ For details, see Kenneth French's online data library.
} 
defense stocks to compute quarterly value-weighted portfolio returns for the defense industry. In addition, we also compute price dividend ratios at the portfolio level, using CRSP data on dividend cash amount (data item DIVAMT). The market return is measured as the return on the value-weighted CRSP market portfolio. The inclusion of these additional variables is motivated by the Campbell and Shiller (1988) expression for the dividend to price ratio:

$$
d_{t}-p_{t}=E_{t} \sum_{j=1}^{\infty} \rho^{j}\left(r_{t+j}^{s}-\Delta d_{t+j}\right)
$$

where $d$ is the $\log$ dividend, $p$ is the $\log$ price, $r^{s}$ is the holding return and $\Delta d$ is the dividend growth rate of a stock. All variables are in real terms. Campbell and Shiller argue that a high log dividend to price ratio implies high expected future holding returns or low expected future dividend growth. For our case, this means that excess returns and dividend to price ratios on defense stocks may contain information about current and future dividend growth in the defense industry and hence information on current and future defense spending growth. A preliminary analysis of the VAR augmented with these two variables revealed that the dividend to price ratio did not contribute to or alter any of our results. Therefore we omit it from our subsequent estimations and report results from the VAR augmented only with excess returns on defense stocks. The state space for the augmented VAR is:

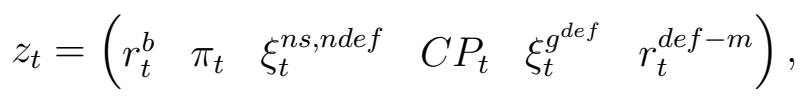

where $r^{d e f-m}=r_{t}^{d e f}-r_{t}^{m}$.

Table 7 reports the estimation results using the VAR specification (14). Our results indicate that the excess returns on defense stocks help predict future defense spending growth; the coefficient of excess returns in the defense spending equation is positive and significant. This provides empirical evidence that defense stock returns do indeed contain new information about future defense spending growth. The variation in defense spending growth is explained better compared to our benchmark VAR: the $R^{2}$ improves to $13.5 \%$. Additionally, (14) proves to be a slightly better specification for explaining the variation in real 
holding returns on government debt- the $R^{2}$ moves up to $14.2 \%$.

[Table 7 about here.]

Table 8 reports the fiscal adjustment betas and the fraction of fiscal risk absorbed through the debt valuation and the surplus channels, using the innovations estimated by our augmented model. All of the estimated beta coefficients are significant at the five percent level and quantitatively very close to our estimates from the benchmark model. The debt valuation beta is -0.36 , implying that a one percent increase in innovations to defense spending growth leads to a 36 basis points decrease in innovations to returns and hence to $9.54 \%$ of fiscal shocks absorbed through the debt valuation channel. Of that, only 1.84 percentage points are financed by a drop in current bond returns and the remaining 7.70 percentage points by a decline in future bond returns. The surplus beta is 2.81 . It implies that $73.68 \%$ of the fiscal risk were absorbed by the surplus channel in the postwar years.

[Table 8 about here.]

\subsection{Defense Stocks: Abnormal Returns}

The excess returns used in the VAR specification (14), $r_{t}^{d e f-m}$, measure movements in defense returns in excess of overall market returns. They may, however, still be correlated with the market return or other systematic risk factors that affect stock returns. We explore the extent to which the industry-specific component of defense stock returns helps predict

defense spending growth. Therefore, we replace $r_{t}^{d e f-m}$ with abnormal returns that control for the known systematic stock market factors.

We construct abnormal returns on defense stocks by regressing the difference between the returns, $r_{t}^{d e f}$, and the three-month riskfree rate, $r_{t}^{R F}$, on the following four factors: the excess return on the market portfolio, MKT, the Fama and French (1993) size and book-tomarket factors, SMB and HML, and the Jegadeesh and Titman (1993) momentum factor, UMD. Specifically, we estimate abnormal returns on defense stocks using rolling regressions on moving windows of three years. That is, at time $t$ we only use information from the last 
three years, and hence exclude observations that are not in the agent's information set. ${ }^{25}$ Our model for the returns on the defense industry is:

$$
\begin{aligned}
r_{t}^{d e f}-r_{t}^{R F}=\alpha & +\beta_{M K T} \mathrm{MKT}_{t}+\beta_{S M B} \mathrm{SMB}_{t}+\beta_{H M L} \mathrm{HML}_{t} \\
& +\beta_{U M D} \mathrm{UMD}_{t}+\varepsilon_{t}^{d e f} .
\end{aligned}
$$

The model is estimated using quarterly data. We refer to the residuals in regression (15) as the abnormal defense stock returns, and denote them by $r_{t}^{d e f, a b n}$. The new state space for the VAR is:

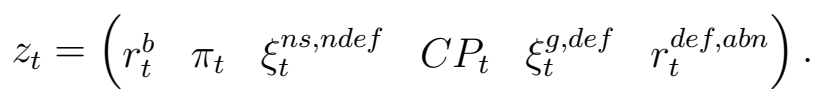

Table 9 reports our estimation results using the alternative augmented VAR specification (16). The variation in defense spending growth explained moves up from our benchmark estimate of $12.6 \%$ to $15.4 \%$. A one standard deviation increase in abnormal returns increases future defense spending growth by $0.88 \%$, while a one standard deviation increase in excess returns results in a smaller increase of $0.49 \%$. This is computed from multiplying the sample standard deviations for abnormal returns (5.15\%) and excess returns (8.84\%) with their respective coefficient estimates. In Table 9, the coefficient associated with abnormal returns in the defense spending equation is positive and significant at the ten percent level. We interpret it as providing additional empirical evidence that defense stock returns do indeed contain new information about future defense spending growth. Once again, the augmented model proves to be a slightly better specification for explaining the variation in real holding returns on government debt- the $R^{2}$ is $14.2 \%$. Table 10 shows that the fraction of fiscal risk absorbed through the debt valuation and the surplus channels remain virtually unchanged at $9.40 \%$ and $72.15 \%$, respectively.

[Table 9 about here.]

\footnotetext{
${ }^{25}$ As an alternative, one could use all prior information to estimate abnormal returns as of time $t$, but this would imply putting less and less weight on recent observations. A moving window of fixed size assigns equal weight to the last three years.
} 
[Table 10 about here.]

We have verified the robustness of our earlier results about the links between the maturity composition of debt and fiscal insurance. We re-estimated the augmented VAR specification (14) after adding the real holding returns on 1-year, 5-year, 10-year, 15-year or 20-year zero-coupon bonds. The fiscal adjustment beta for the debt valuation channel more than doubles from -0.29 at the 1-year maturity to -0.67 at the 20 -year maturity, confirming our earlier results that longer term debt is more effective in absorbing fiscal shocks than shorter term debt. The fiscal insurance estimate increases with maturity and ranges from 7.62 percent to 17.43 percent.

\section{Conclusion}

The U.S. government's finances, especially in times of high spending such as wars, have been and continue to be a topic of importance for researchers, policymakers and the taxpaying public. There is, however, little empirical work on quantifying the adjustment channels that help stabilize the government's fiscal balances following expenditure shocks. Our main contribution is developing a framework to identify and quantify these fiscal adjustment channels. Our framework does not rely on any particular fiscal model, nor does it require taking a stance on asset market completeness or government preferences. We make use of the government's intertemporal budget constraint only, a common feature of all dynamic fiscal models. We show that the log-linearized version of the government's intertemporal budget constraint implies the following. Surprise spending needs must be financed either through surprise increases in primary surpluses or through a surprise decline in the market value of government debt. We use unstructured VARs to obtain empirical estimates of fiscal shocks, innovations to primary surpluses and innovations to holding returns on government debt. We then use these estimates to quantify the response of primary surpluses and debt returns to fiscal shocks. Our estimates show that the in the postwar era, the U.S. government has financed more than $73 \%$ of its surprise spending needs by running primary surpluses and over $9 \%$ of its surprise spending needs by delivering real capital losses to bond holders. The latter 
result indicates that the U.S. government was able to achieve a limited, but non-negligible degree of fiscal insurance through bond markets.

Our second contribution concerns the link between the degree of fiscal insurance and the maturity composition of the government's debt portfolio. We provide empirical evidence that long-term debt is a better instrument for absorbing fiscal risk. More specifically, we show that the fraction of fiscal risk absorbed by debt of 1-year maturity is almost $8 \%$, whereas this fraction is more than double of that amount at about $18 \%$ for debt of 20 -year maturity. These results have implications for active management of government debt. They indicate that if the response of the term structure to expenditure shocks is taken as given, the government can use the bond markets more effectively to finance fiscal shocks by lengthening the maturity of its bond portfolio, and without taking extreme portfolio positions.

Our third contribution is an alternative VAR specification that estimates fiscal shocks more precisely and helps resolve the "timing" issue associated with using only aggregate data to identify these shocks. In this alternative specification, we include returns on defense stocks as an additional explanatory variable. Defense stock returns respond contemporaneously to news about defense spending growth and hence predict future defense spending growth. Our approach has already been adopted by Fisher and Peters (2009), who use similar defense stock variables in their VAR to identify government spending shocks and estimate the response of consumption, real wages, hours and other real macroeconomic variables to such shocks. Our emphasis is on fiscal adjustment channels. The augmented VAR specification confirms our earlier results: the U.S. government has made some use of bond markets to finance its surprise spending needs in the postwar era. More than $9 \%$ of fiscal shocks were absorbed by a drop in current and future returns. 


\section{References}

Aiyagari, R., Marcet, A., Sargent, T., Seppala, J., 2002. Optimal taxation without state contingent debt. Journal of Political Economy 110, 1220-1254.

Akaike, H., 1974. A new look at the statistical model identification. IEEE Transactions on Automatic Control 19, 716-723.

Angeletos, G., 2002. Fiscal policy with non-contingent debt and the optimal maturity structure. Quarterly Journal of Economics 117, 1105-1131.

Barro, R., 1979. On the determination of the public debt. Journal of Political Economy 87, 940-971.

Barro, R., 1997. Optimal management of indexed and nominal debt, NBER working paper 6197.

Bizer, D., Durlauf, S., 1990. Testing a positive theory of government finance. Journal of Monetary Economics 26, 123-141.

Bohn, H., 1988. Why do we have nominal debt? Journal of Monetary Economics 21, 127-140.

Bohn, H., 1998. The behavior of public debt and deficits. Quarterly Journal of Economics 113, 949-963.

Buera, F., Nicolini, J., 2004. Optimal maturity of government debt without state contingent bonds. Journal of Monetary Economics 51, 531-554.

Campbell, J., 1993. Asset pricing without consumption data. American Economic Review $83,487-512$.

Campbell, J., 1995. Some lessons from the yield curve. Journal of Economic Perspectives 9, $129-152$.

Campbell, J., Shiller, R., 1988. The dividend price ratio and expectations of future dividends and discount factors. Review of Financial Studies 1, 195-227.

Cochrane, J., Piazzesi, M., 2005. Bond risk premia. American Economic Review 95, 138-160.

Correia, I., Nicolini, J., Teles, P., 2008. Optimal fiscal and monetary policy: Equivalence results. Journal of Political Economy 116, 141-170.

Fama, E., French, K., 1993. Common risk factors in the returns on stock and bonds. Journal of Financial Economics 33, 3-56.

Faraglia, E., Marcet, A., Scott, A., 2008a. Fiscal insurance and debt management in OECD economies. Economic Journal 118, 363-386. 
Faraglia, E., Marcet, A., Scott, A., 2008b. In search of a theory of debt management, UFAE and IAE working papers 743.08 .

Fisher, J., Peters, R., 2009. Using stock returns to identify government spending shocks, Working paper, Chicago Federal Reserve Bank.

Gourinchas, P., Rey, H., 2007. International financial adjustment. Journal of Political Economy $115,665-703$.

Hall, G., Sargent, T., 1997. Accounting for the federal government's cost of funds. Economic Perspectives 21, 18-28.

Hess, G., 1993. A test of the theory of optimal taxes for the United States 1869-1989. Review of Economics and Statistics 75, 712-716.

Hodrick, R., Prescott, E., 1997. Post-war U.S. business cycles: An empirical investigation. Journal of Money, Credit and Banking 29, 1-16.

Jegadeesh, N., Titman, S., 1993. Returns to buying winners and selling losers: Implications for stock market efficiency. Journal of Finance 48, 65-91.

Lustig, H., Sleet, C., Yeltekin, S., 2008. Fiscal hedging with nominal assets. Journal of Monetary Economics 55, 710-727.

Marcet, A., Scott, A., 2009. Debt and deficit fluctuations and the structure of bond markets. Journal of Economic Theory 144, 473-501.

Nelson, R., Siegel, F., 1987. Parsimonious modeling of yield curves. Journal of Business 60, 473-489.

Ramey, V., 2009. Identifying government spending shocks: It's all in the timing, Working paper, University of California, San Diego.

Sahasakul, C., 1986. The U.S. evidence on optimal taxes over time. Journal of Monetary Economics 18, 251-275.

Said, E., Dickey, D., 1984. Testing for unit roots in autoregressive moving average models of unknown order. Biometrika 71, 599-607.

Schwarz, G., 1978. Estimating the dimension of a model. Annals of Statistics 6, 461-464.

Scott, A., 2007. Optimal taxation and oecd labor taxes. Journal of Monetary Economics 54, 925-944.

Sleet, C., 2004. Optimal taxation with private government information. Review of Economic Studies 71, 1217-1239. 


\section{Appendix A. Log-linearization of the Government Budget Constraint}

We start with the dynamic budget constraint of the government. All variables are expressed in real terms. Let $B_{t}$ denotes the time- $t$ real market value of government debt outstanding at the beginning of the period. The government budget constraint is given by:

$$
B_{t+1}=R_{t+1}^{b}\left(B_{t}-S_{t}\right),
$$

where $R_{t+1}^{b}$ is the gross real return on government debt between $t$ and $t+1$. The government's real primary surplus, $S_{t}=T_{t}-G_{t}$, is computed as the difference between receipts $T_{t}$ and expenditures $G_{t}$. $T_{t}$ also includes seignorage revenue. The growth rate of government debt can be stated simply as the gross return times one minus the primary surplus to debt ratio:

$$
\frac{B_{t+1}}{B_{t}}=R_{t+1}^{b}\left(1-\frac{S_{t}}{B_{t}}\right)
$$

We assume that $B_{t}>0$ and $B_{t}>S_{t}$, for all $t$. Additionally, we assume that the log receipts to debt ratio, $\log \left(T_{t} / B_{t}\right)$, and the $\log$ spending to debt ratio, $\log \left(G_{t} / B_{t}\right)$, are stationary around their respective average values $\overline{\tau b}$ and $\overline{g b}$, and that $\exp (\overline{\tau b})-\exp (\overline{g b})$ is between 0 and 1. Using lower case letters to denote logs, Equation (A.1) may be rewritten as:

$$
\Delta b_{t+1}= \begin{cases}r_{t+1}^{b}+\log \left(1-\exp \left(s_{t}-b_{t}\right)\right), & \text { if } S_{t}>0 \\ r_{t+1}^{b}+\log \left(1+\exp \left(d_{t}-b_{t}\right)\right), & \text { if } D_{t}=-S_{t}>0\end{cases}
$$

where we distinguish between the case in which the government is running surpluses and the case in which it is running deficits. If the government only ran surpluses, then we could expand the right-hand side of the log budget constraint as a function of $s_{t}-b_{t}$ around $\overline{s b}=\overline{\log S B}$ :

$$
\log \left(1-\exp \left(s_{t}-b_{t}\right)\right) \approx \log (1-\exp (\overline{s b}))-\frac{\exp (\overline{s b})}{1-\exp (\overline{s b})}\left[\left(s_{t}-b_{t}\right)-\overline{s b}\right]
$$

Since governments do run deficits, an alternative expansion is required. We rewrite 
$\log \left(1-S_{t} / B_{t}\right)$ as $\log \left(1-\exp \left(\tau_{t}-b_{t}\right)+\exp \left(g_{t}-b_{t}\right)\right)$ and expand around $(\overline{\tau b}, \overline{g b})$. We obtain:

$$
\begin{aligned}
\log \left(1-\frac{S_{t}}{B_{t}}\right) \approx & \log (1-\exp (\overline{\tau b})+\exp (\overline{g b})) \\
& -\frac{\mu_{s b}}{1-\mu_{s b}}\left(\frac{\mu_{\tau b}\left(\tau_{t}-b_{t}-\overline{\tau b}\right)-\mu_{g b}\left(g_{t}-b_{t}-\overline{g b}\right)}{\mu_{s b}}\right) \\
= & K-\frac{\mu_{s b}}{1-\mu_{s b}}\left(\frac{\mu_{\tau b}}{\mu_{\tau b}-\mu_{g b}} \tau_{t}-\frac{\mu_{g b}}{\mu_{\tau b}-\mu_{g b}} g_{t}-b_{t}\right),
\end{aligned}
$$

where $K$ absorbs unimportant constants. The weights are defined as $\mu_{s b}=\mu_{\tau b}-\mu_{g b}$, with $\mu_{\tau b}=\exp (\overline{\tau b})$ and $\mu_{g b}=\exp (\overline{g b})$.

The approximation in (A.2) implies the following law of motion for debt:

$$
\Delta b_{t+1}=r_{t+1}^{b}+\left(1-\frac{1}{\rho}\right)\left(n s_{t}-b_{t}\right)
$$

where $\rho=1-\mu_{s b}$. Rearranging terms produces:

$$
n s_{t}-b_{t}=\rho r_{t+1}^{b}-\rho \Delta n s_{t+1}+\rho\left(n s_{t+1}-b_{t+1}\right)
$$

This is a first-order difference equation that can be solved by repeated substitution for the weighted log surplus to debt ratio. Taking conditional expectations and imposing the tail condition $\lim _{j \rightarrow \infty} E_{t} \rho^{j}\left(n s_{t+j}-b_{t+j}\right)=0$, we obtain:

$$
n s_{t}-b_{t}=E_{t} \sum_{j=1}^{\infty} \rho^{j}\left(r_{t+j}^{b}-\Delta n s_{t+j}\right)
$$

Equation (A.3) implies:

$$
n s_{t+1}-b_{t+1}-E_{t}\left(n s_{t+1}-b_{t+1}\right)=\left(E_{t+1}-E_{t}\right) \sum_{j=1}^{\infty} \rho^{j} r_{t+j+1}^{b}-\left(E_{t+1}-E_{t}\right) \sum_{j=1}^{\infty} \rho^{j} \Delta n s_{t+j+1} .
$$


Substituting $r_{t+1}^{b}-E_{t} r_{t+1}^{b}$ for $b_{t+1}-E_{t} b_{t+1}$ yields:

$$
n s_{t+1}-E_{t} n s_{t+1}=\left(E_{t+1}-E_{t}\right) \sum_{j=0}^{\infty} \rho^{j} r_{t+j+1}^{b}-\left(E_{t+1}-E_{t}\right) \sum_{j=1}^{\infty} \rho^{j} \Delta n s_{t+j+1} .
$$

\section{Appendix B. Fiscal Data}

The source for most of our fiscal budget data is NIPA Table 3.2, Government Current Receipts and Expenditures, seasonally adjusted and measured in billions of dollars. Government expenditures $G$ include current expenditures (Line 41), gross government investment (Line 42), and capital transfer payments (Line 43). We subtract consumption of fixed capital (Line 45) and debt interest payments (Line 29) from current expenditures. We separate total government expenditure into two components: defense spending, $G^{\text {def }}$ and non-defense spending, $G^{\text {ndef }}$. National defense spending data are from NIPA Table 3.9.5., Line 11 (national defense expenditures). They are seasonally adjusted and measured in billions of dollars. We adjust $G^{\text {def }}$ by subtracting the proportion of consumption of fixed capital that's attributable to defense spending (as a percentage of total spending). We compute $G^{\text {ndef }}$ by subtracting $G^{\text {def }}$ from total expenditures $G$.

We calculate government receipts, $T$, by taking total receipts (Line 37 of NIPA Table 3.2), which includes current tax receipts, contributions for social insurance, income receipts on other assets and current transfer receipts, and adding on seignorage revenue. We compute seignorage revenue at time $t$ as $\frac{M_{t}-M_{t-1}}{C P I_{t}}$, where $M_{t}$ is the monetary base at time $t$ and $C P I_{t}$ is the price level defined by the consumer price index at $t$. Therefore real seignorage revenue includes the "inflation tax", the resources generated from adjusting the real value of the existing monetary base, and the real value of revenues from a change in the monetary base. The monetary base data are the St. Louis Adjusted Monetary Base (AMBSL) series, seasonally adjusted and measured in billions of dollars. 
Table 1: Benchmark VAR Estimates

This table reports the results of the benchmark VAR estimation. The benchmark VAR includes five variables, one lag and uses quarterly data. T-statistics for the GMM estimates are reported in parentheses. We use the Newey-West variance-covariance matrix with four lags as the weighting matrix. The last column reports the R-squared. The sample period is 1946.I-2008.III.

\begin{tabular}{lcccccc}
\hline & $r_{t-1}^{b}$ & $\pi_{t-1}$ & $\xi_{t-1}^{n s, n d e f}$ & $C P_{t-1}$ & $\xi_{t-1}^{g, d e f}$ & $R^{2}$ \\
\hline$r_{t}^{b}$ & -0.0999 & -0.3784 & -0.0019 & 1.9802 & -0.0051 & 0.1353 \\
& $(-0.9935)$ & $(-2.1090)$ & $(-0.7394)$ & $(4.5360)$ & $(-0.2569)$ & \\
$\pi_{t}$ & 0.0220 & 0.5195 & 0.0019 & -0.1504 & -0.0031 & 0.2541 \\
& $(0.6618)$ & $(6.1524)$ & $(1.2353)$ & $(-0.8226)$ & $(-0.2749)$ & \\
$\xi_{t}^{n s, n d e f}$ & 0.0557 & 4.1801 & 0.0848 & -8.3343 & -0.3712 & 0.0196 \\
& $(0.0261)$ & $(0.7321)$ & $(0.5727)$ & $(-0.6256)$ & $(-0.6302)$ & \\
$C P_{t}$ & 0.0073 & 0.0221 & -0.0002 & 0.9154 & 0.0002 & 0.8763 \\
& $(0.8683)$ & $(2.0545)$ & $(-1.3978)$ & $(33.4974)$ & $(0.2663)$ & \\
$\xi_{t}^{g, d e f}$ & -0.0276 & 0.8138 & 0.0061 & -2.7649 & 0.0873 & 0.1260 \\
& $(-0.1906)$ & $(1.6801)$ & $(0.5760)$ & $(-1.5209)$ & $(0.4327)$ & \\
\hline \multirow{2}{*}{} & & & & & & \\
\hline
\end{tabular}


Table 2: Correlations between Innovations

This table reports the standard deviations (diagonals) and the correlations (off-diagonals) of the news variables constructed from the benchmark VAR. The sample period is 1946.I-2008.III.

\begin{tabular}{lccc}
\hline & $h_{t+1}\left(r^{b}\right)$ & $h_{t+1}\left(g^{\text {def }}\right)$ & $h_{t+1}\left(n s^{\text {ndef }}\right)$ \\
\hline$h_{t+1}\left(r^{b}\right)$ & 0.04 & & \\
$h_{t+1}\left(g^{\text {def }}\right)$ & -0.72 & 0.08 & \\
$h_{t+1}\left(n s^{\text {ndef }}\right)$ & -0.42 & 0.40 & 0.58 \\
\hline
\end{tabular}


Table 3: Fiscal Adjustment Results

This table reports the results from regressing $h_{t+1}\left(r^{b}\right)$, its components $h_{t+1}^{c}\left(r^{b}\right)$ and $h_{t+1}^{f}\left(r^{b}\right)$, and $h_{t+1}\left(n s^{\text {ndef }}\right)$ on $h_{t+1}\left(g^{\text {def }}\right)$, as described in Equations (11) and (12). The first two columns show the intercept and the fiscal adjustment beta, with their t-statistics in parentheses. The third column reports the R-squared, and the final column shows the fraction of expenditure shocks financed by each channel. Innovations are computed from the benchmark VAR. The sample period is 1946.I2008.III.

\begin{tabular}{lcccc}
\hline & $\beta_{0}$ & $\beta_{1}$ & $R^{2}$ & Fraction \\
\hline$h^{c}\left(r^{b}\right)$ & 0.0003 & -0.0690 & 0.0671 & 0.0181 \\
& $(0.2179)$ & $(-2.2625)$ & & \\
$h^{f}\left(r^{b}\right)$ & 0.0017 & -0.2973 & 0.5620 & 0.0780 \\
& $(1.0098)$ & $(-5.2064)$ & & \\
$h\left(r^{b}\right)$ & 0.0020 & -0.3663 & 0.5200 & 0.0961 \\
& $(0.8841)$ & $(-4.8947)$ & & \\
$h\left(n s^{\text {ndef }}\right)$ & -0.0001 & 2.7962 & 0.1586 & 0.7334 \\
& $(-0.0035)$ & $(5.2112)$ & & \\
\hline
\end{tabular}


Table 4: Fiscal Adjustment Betas

This table reports the results from regressing $h_{t+1}\left(r^{b}\right)$ and $h_{t+1}\left(n s^{n d e f}\right)$ on $h_{t+1}\left(g^{\text {def }}\right)$, as described in Equations (11) and (12). The first column shows the fiscal adjustment betas, with their tstatistics in parentheses. The second column reports the R-squared, and the final column shows the fraction of expenditure shocks financed by each channel. We report results for several smoothing parameters for the HP filter. Innovations are computed from the benchmark VAR. The sample period is 1946.I-2008.III.

\begin{tabular}{|c|c|c|c|c|}
\hline HP cycle & & $\beta_{1}$ & $R^{2}$ & Fraction \\
\hline \multirow[t]{2}{*}{ 9.9-year* } & $\beta_{1}^{r}$ & $\begin{array}{c}-0.4297 \\
(-4.2723)\end{array}$ & 0.4892 & 0.1127 \\
\hline & $\beta_{1}^{n s}$ & $\begin{array}{c}2.1389 \\
(4.9075)\end{array}$ & 0.0800 & 0.5610 \\
\hline \multirow[t]{2}{*}{ 15-year } & $\beta_{1}^{r}$ & $\begin{array}{c}-0.3663 \\
(-4.8947)\end{array}$ & 0.5200 & 0.0961 \\
\hline & $\beta_{1}^{n s}$ & $\begin{array}{c}2.7962 \\
(5.2112)\end{array}$ & 0.1586 & 0.7334 \\
\hline \multirow[t]{2}{*}{ 20-year } & $\beta_{1}^{r}$ & $\begin{array}{c}-0.3111 \\
(-5.7880)\end{array}$ & 0.5658 & 0.0816 \\
\hline & $\beta_{1}^{n s}$ & $\begin{array}{c}3.3756 \\
(7.3987)\end{array}$ & 0.2786 & 0.8854 \\
\hline \multirow[t]{2}{*}{ 30-year } & $\beta_{1}^{r}$ & $\begin{array}{c}-0.2489 \\
(-6.6415)\end{array}$ & 0.5885 & 0.0653 \\
\hline & $\beta_{1}^{n s}$ & $\begin{array}{c}3.9009 \\
(12.1334)\end{array}$ & 0.4409 & 1.0232 \\
\hline \multirow[t]{2}{*}{ 50-year } & $\beta_{1}^{r}$ & $\begin{array}{c}-0.2204 \\
(-7.0654)\end{array}$ & 0.5960 & 0.0578 \\
\hline & $\beta_{1}^{n s}$ & $\begin{array}{c}4.1550 \\
(15.9570)\end{array}$ & 0.5249 & 1.0898 \\
\hline
\end{tabular}

*This cycle is actually 9.93 years, corresponding to a HP filter smoothing factor of 1600, the smoothing factor used in business cycle analysis. 
Table 5: Real Bond Holding Returns by Maturity

This table reports the average quarterly real holding returns (in percentage terms) on bonds of different maturities (in years). Standard deviations are reported in parentheses. Zero-coupon yield curves are constructed from CRSP data. The sample period is 1946.I-2008.III.

\begin{tabular}{lccccc}
\hline Maturity & 1 & 5 & 10 & 15 & 20 \\
\hline Mean (\%) & 0.30 & 0.43 & 0.48 & 0.46 & 0.38 \\
Std dev (\%) & $(1.52)$ & $(3.58)$ & $(5.74)$ & $(9.78)$ & $(18.05)$ \\
\hline
\end{tabular}


Table 6: Fiscal Adjustment Betas for Each Maturity

This table reports fiscal adjustment betas, maturity by maturity (in years). The first two columns show the intercept and the beta, with their t-statistics in parentheses. The third column reports the R-squared, whereas the final column shows the fraction of fiscal shocks financed. Innovations are computed from the VAR in (13). The sample period is 1946.I-2008.III.

\begin{tabular}{lcccc}
\hline Maturity & $\beta_{0}$ & $\beta_{1}^{r, k}$ & $R^{2}$ & Fraction \\
\hline 1 & 0.0016 & -0.2927 & 0.5717 & 0.0768 \\
& $(0.9411)$ & $(-5.6089)$ & & \\
5 & 0.0023 & -0.4208 & 0.4229 & 0.1104 \\
& $(0.7721)$ & $(-4.4156)$ & & \\
10 & 0.0029 & -0.4872 & 0.2919 & 0.1278 \\
& $(0.6851)$ & $(-3.4240)$ & & \\
15 & 0.0034 & -0.5599 & 0.1822 & 0.1469 \\
& $(0.5173)$ & $(-2.6632)$ & & \\
20 & 0.0036 & -0.6745 & 0.0974 & 0.1769 \\
& $(0.3238)$ & $(-2.0437)$ & & \\
\hline
\end{tabular}


Table 7: Augmented VAR Estimates: Excess Returns on Defense Stocks

This table reports the results of the augmented VAR estimation. The augmented VAR includes the five variables from the benchmark VAR plus the excess returns on the Fama and French "Guns" portfolio, $r^{d e f-m}$. It has one lag and uses quarterly data. T-statistics for the GMM estimates are reported in parentheses. We use the Newey-West variance-covariance matrix with four lags as the weighting matrix. The last column reports the R-squared. The sample period is 1946.I-2008.III.

\begin{tabular}{lccccccc}
\hline & $r_{t-1}^{b}$ & $\pi_{t-1}$ & $\xi_{t-1}^{\text {ns,ndef }}$ & $C P_{t-1}$ & $\xi_{t-1}^{g, \text { def }}$ & $r_{t-1}^{\text {def-m }}$ & $R^{2}$ \\
\hline$r_{t}^{b}$ & -0.1100 & -0.3874 & -0.0018 & 1.9822 & -0.0039 & 0.0213 & 0.1416 \\
& $(-1.1188)$ & $(-2.1251)$ & $(-0.7148)$ & $(4.4558)$ & $(-0.1893)$ & $(1.3103)$ & \\
$\pi_{t}$ & 0.0248 & 0.5220 & 0.0019 & -0.1509 & -0.0035 & -0.0060 & 0.2563 \\
& $(0.7289)$ & $(6.0505)$ & $(1.1931)$ & $(-0.8042)$ & $(-0.3017)$ & $(-0.6843)$ & \\
$\xi_{t}^{n s, n d e f}$ & -0.1391 & 4.0050 & 0.0855 & -8.2952 & -0.3476 & 0.4101 & 0.0249 \\
& $(-0.0656)$ & $(0.6784)$ & $(0.5684)$ & $(-0.6141)$ & $(-0.5756)$ & $(1.1291)$ & \\
$C P_{t}$ & 0.0072 & 0.0220 & -0.0002 & 0.9154 & 0.0002 & 0.0002 & 0.8763 \\
& $(0.8425)$ & $(1.9985)$ & $(-1.3566)$ & $(32.6842)$ & $(0.2749)$ & $(0.2376)$ & \\
$\xi_{t}^{g, d e f}$ & -0.0541 & 0.7900 & 0.0062 & -2.7595 & 0.0905 & 0.0558 & 0.1348 \\
& $(-0.3655)$ & $(1.6001)$ & $(0.5830)$ & $(-1.4908)$ & $(0.4399)$ & $(2.0732)$ & \\
$r_{t}^{\text {def }-m}$ & -0.2368 & -0.5145 & -0.0003 & 2.0267 & 0.1312 & 0.0565 & 0.0266 \\
& $(-0.6912)$ & $(-0.7083)$ & $(-0.0220)$ & $(1.4655)$ & $(2.6914)$ & $(0.7673)$ & \\
\hline
\end{tabular}


Table 8: Fiscal Adjustment Results: Excess Returns on Defense Stocks

This table reports the results from regressing $h_{t+1}\left(r^{b}\right)$, its components $h_{t+1}^{c}\left(r^{b}\right)$ and $h_{t+1}^{f}\left(r^{b}\right)$, and $h_{t+1}\left(n s^{\text {ndef }}\right)$ on $h_{t+1}\left(g^{\text {def }}\right)$, as described in Equations (11) and (12). The first two columns show the intercept and the fiscal adjustment beta, with their t-statistics in parentheses. The third column reports the R-squared, and the final column shows the fraction of expenditure shocks financed by each channel. Innovations are computed from the augmented VAR in Table 7. The sample period is 1946.I-2008.III.

\begin{tabular}{lcccc}
\hline & $\beta_{0}$ & $\beta_{1}$ & $R^{2}$ & Fraction \\
\hline$h^{c}\left(r^{b}\right)$ & 0.0003 & -0.0702 & 0.0704 & 0.0184 \\
& $(0.2351)$ & $(-2.3066)$ & & \\
$h^{f}\left(r^{b}\right)$ & 0.0018 & -0.2934 & 0.5480 & 0.0770 \\
& $(1.0169)$ & $(-5.1858)$ & & \\
$h\left(r^{b}\right)$ & 0.0021 & -0.3636 & 0.5158 & 0.0954 \\
& $(0.9090)$ & $(-4.9286)$ & & \\
$h\left(n s^{\text {ndef }}\right)$ & 0.0002 & 2.8089 & 0.1604 & 0.7368 \\
& $(0.0046)$ & $(5.3221)$ & & \\
\hline
\end{tabular}


Table 9: Augmented VAR Estimates: Abnormal Returns on Defense Stocks

This table reports the results of the augmented VAR estimation. The augmented VAR includes the five variables from the benchmark VAR plus the abnormal returns on the Fama and French "Guns" portfolio, $r^{d e f, a b n}$. It has one lag and uses quarterly data. T-statistics for the GMM estimates are reported in parentheses. We use the Newey-West variance-covariance matrix with four lags as the weighting matrix. The last column reports the R-squared. The sample period is 1946.I-2008.III.

\begin{tabular}{lccccccc}
\hline & $r_{t-1}^{b}$ & $\pi_{t-1}$ & $\xi_{t-1}^{\text {ns,ndef }}$ & $C P_{t-1}$ & $\xi_{t-1}^{g, \text { def }}$ & $r_{t-1}^{\text {def,abn }}$ & $R^{2}$ \\
\hline$r_{t}^{b}$ & -0.0963 & -0.3604 & -0.0014 & 1.9695 & -0.0064 & 0.0380 & 0.1421 \\
& $(-0.9465)$ & $(-1.9834)$ & $(-0.5538)$ & $(4.3969)$ & $(-0.3057)$ & $(1.2780)$ & \\
$\pi_{t}$ & 0.0210 & 0.5143 & 0.0018 & -0.1473 & -0.0027 & -0.0110 & 0.2566 \\
& $(0.6055)$ & $(6.0028)$ & $(1.1241)$ & $(-0.7954)$ & $(-0.2350)$ & $(-0.6824)$ & \\
$\xi_{t}^{n s, n d e f}$ & 0.0487 & 4.1453 & 0.0839 & -8.3137 & -0.3686 & -0.0737 & 0.0197 \\
& $(0.0221)$ & $(0.7249)$ & $(0.5356)$ & $(-0.6048)$ & $(-0.6021)$ & $(-0.1027)$ & \\
$C P_{t}$ & 0.0073 & 0.0222 & -0.0002 & 0.9153 & 0.0002 & 0.0003 & 0.8763 \\
& $(0.8498)$ & $(1.9988)$ & $(-1.3200)$ & $(32.4777)$ & $(0.2428)$ & $(0.1768)$ & \\
$\xi_{t}^{g, d e f}$ & -0.0114 & 0.8944 & 0.0081 & -2.8125 & 0.0815 & 0.1706 & 0.1540 \\
& $(-0.0801)$ & $(1.8818)$ & $(0.8119)$ & $(-1.5296)$ & $(0.4100)$ & $(1.9671)$ & \\
$r_{t}^{\text {def,abn }}$ & -0.2935 & -0.1915 & 0.0004 & 1.0532 & 0.1178 & 0.0288 & 0.0580 \\
& $(-1.8407)$ & $(-0.4259)$ & $(0.0554)$ & $(1.2770)$ & $(4.1135)$ & $(0.3958)$ & \\
\hline
\end{tabular}


Table 10: Fiscal Adjustment Results: Abnormal Returns on Defense Stocks

This table reports the results from regressing $h_{t+1}\left(r^{b}\right)$, its components $h_{t+1}^{c}\left(r^{b}\right)$ and $h_{t+1}^{f}\left(r^{b}\right)$, and $h_{t+1}\left(n s^{n d e f}\right)$ on $h_{t+1}\left(g^{\text {def }}\right)$, as described in Equations (11) and (12). The first two columns show the intercept and the fiscal adjustment beta, with their t-statistics in parentheses. The third column reports the R-squared, and the final column shows the fraction of expenditure shocks financed by each channel. Innovations are computed from the augmented VAR in Table 9. The sample period is 1946.I-2008.III.

\begin{tabular}{lcccc}
\hline & $\beta_{0}$ & $\beta_{1}$ & $R^{2}$ & Fraction \\
\hline$h^{c}\left(r^{b}\right)$ & 0.0003 & -0.0736 & 0.0793 & 0.0193 \\
& $(0.2390)$ & $(-2.4640)$ & & \\
$h^{f}\left(r^{b}\right)$ & 0.0017 & -0.2846 & 0.5329 & 0.0746 \\
& $(0.9969)$ & $(-5.1066)$ & & \\
$h\left(r^{b}\right)$ & 0.0020 & -0.3582 & 0.5205 & 0.0940 \\
& $(0.9077)$ & $(-4.9918)$ & & \\
$h\left(n s^{\text {ndef }}\right)$ & -0.0003 & 2.7509 & 0.1588 & 0.7215 \\
& $(-0.0079)$ & $(5.6460)$ & & \\
\hline
\end{tabular}


Figure 1: Government Receipts and Spending. This plot shows the logarithm of the receipts to debt ratio, $\log \left(T_{t} / B_{t}\right)$, and the logarithm of the spending to debt ratio, $\log \left(G_{t} / B_{t}\right)$. The sample period is 1946.I-2008.III.

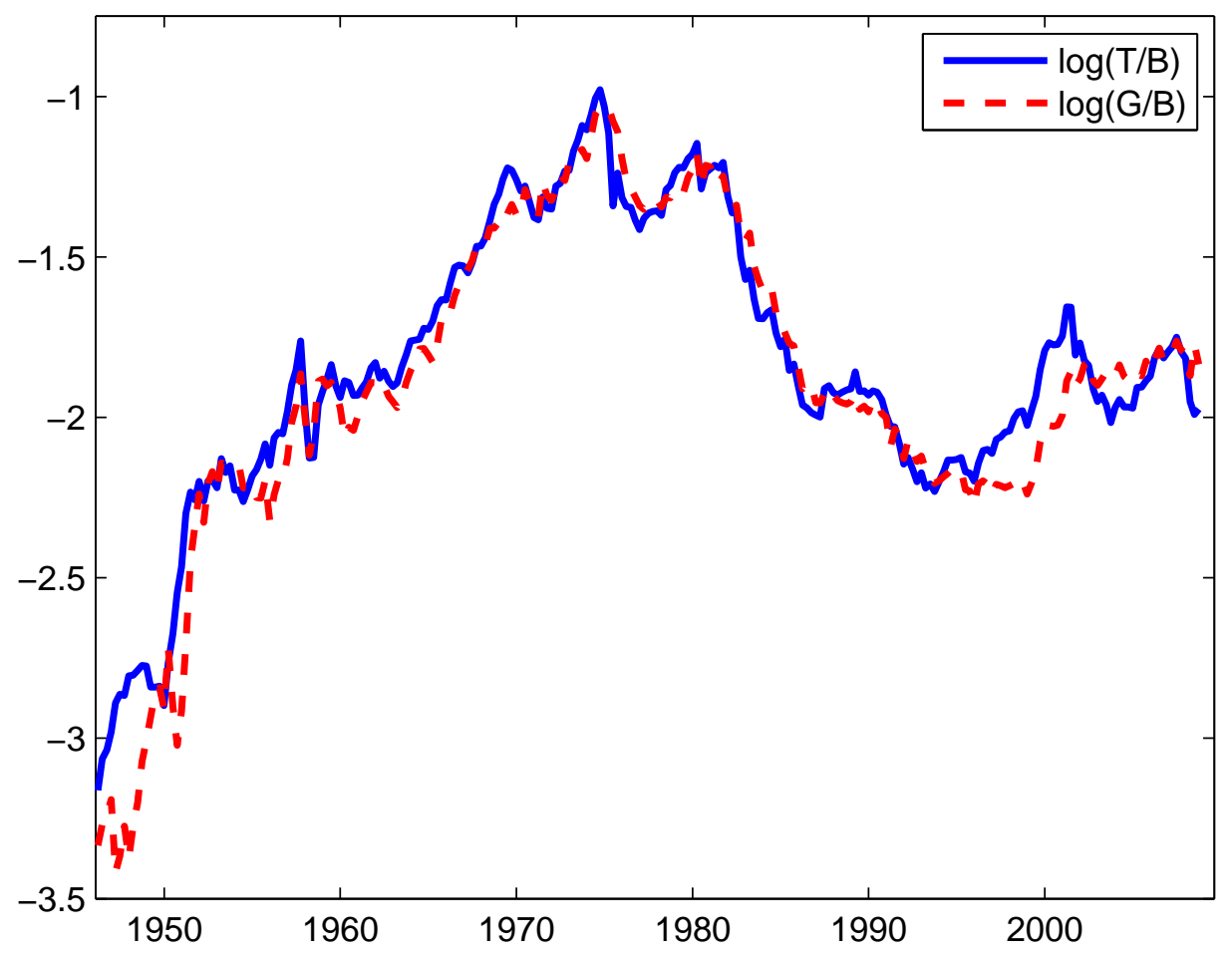


Figure 2: Real Holding Returns on Government Debt. This plot shows the time series of value weighted real holding returns on the government debt portfolio, $r_{t}^{b}$. The sample period is 1946.I-2008.III.

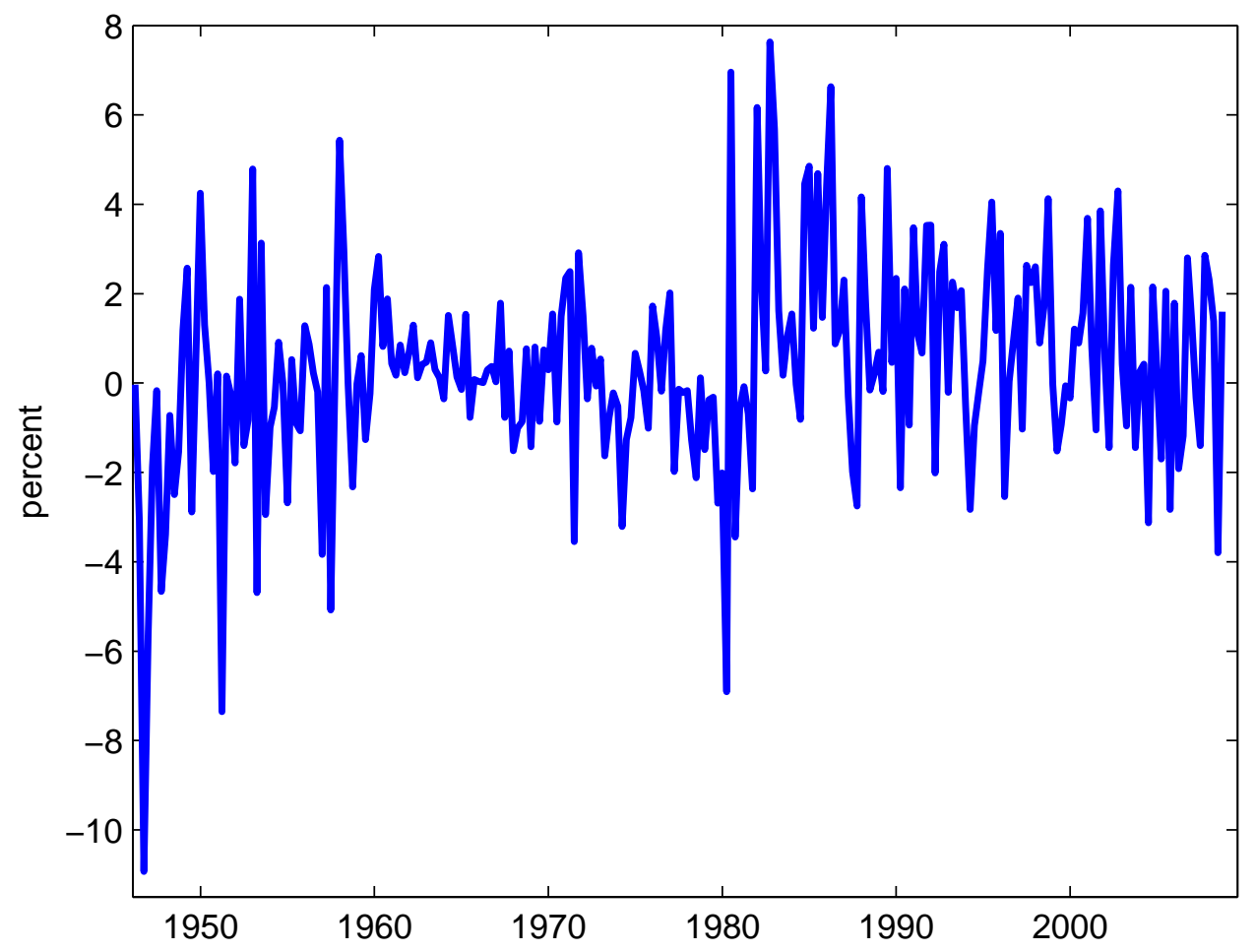


Figure 3: Real Defense Spending. This plot shows the time series of real defense spending from 1939 to 2008, as well as the Ramey (2009) defense shock dates (vertical lines).

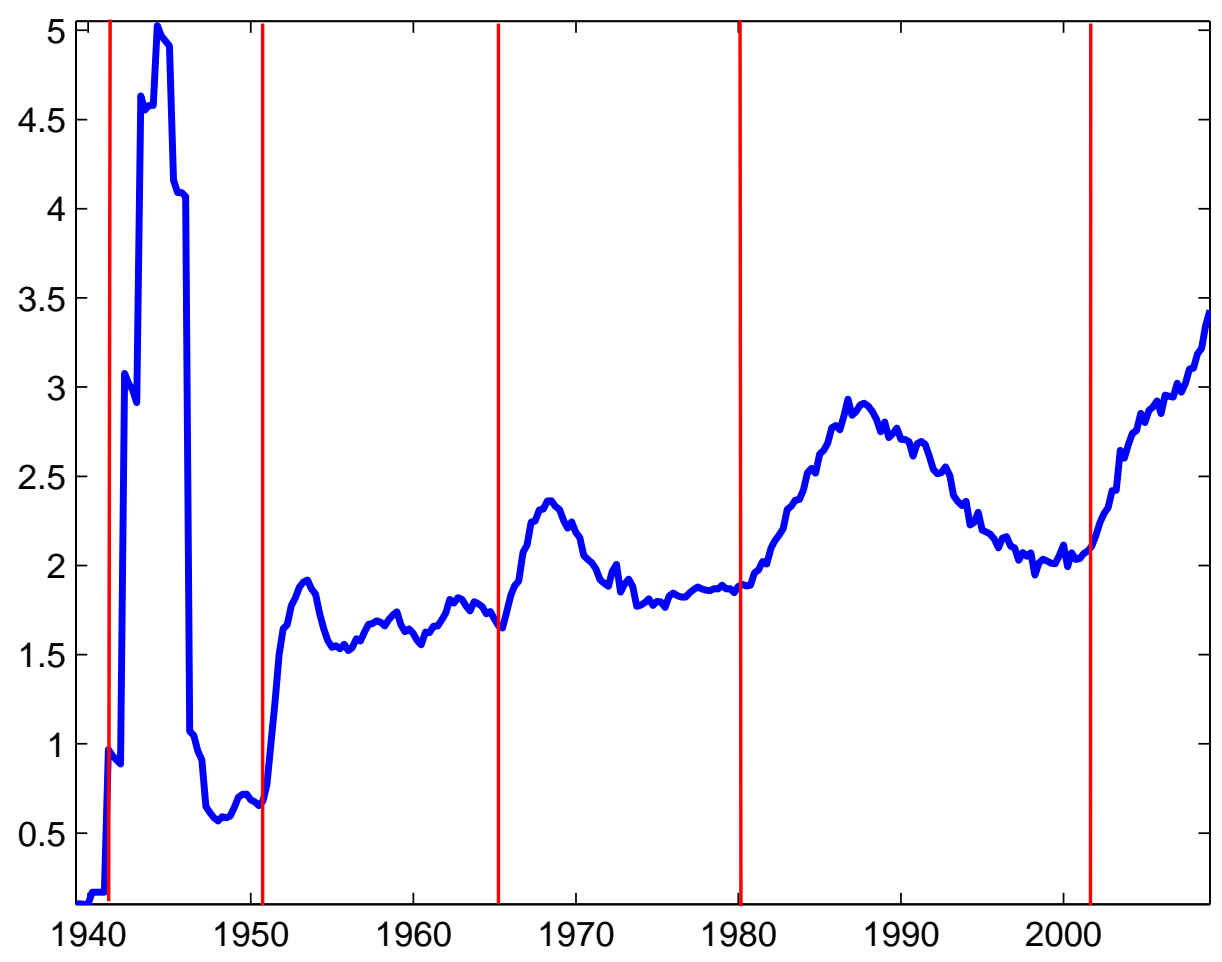


Figure 4: Maturity Structure of Publicly Held Debt. This plot shows the face value weighted and market value weighted maturity (in years) of publicly held debt between 1939.I-2008.III. The vertical dotted line marks 1946.I, the beginning of the sample period for our empirical analysis.

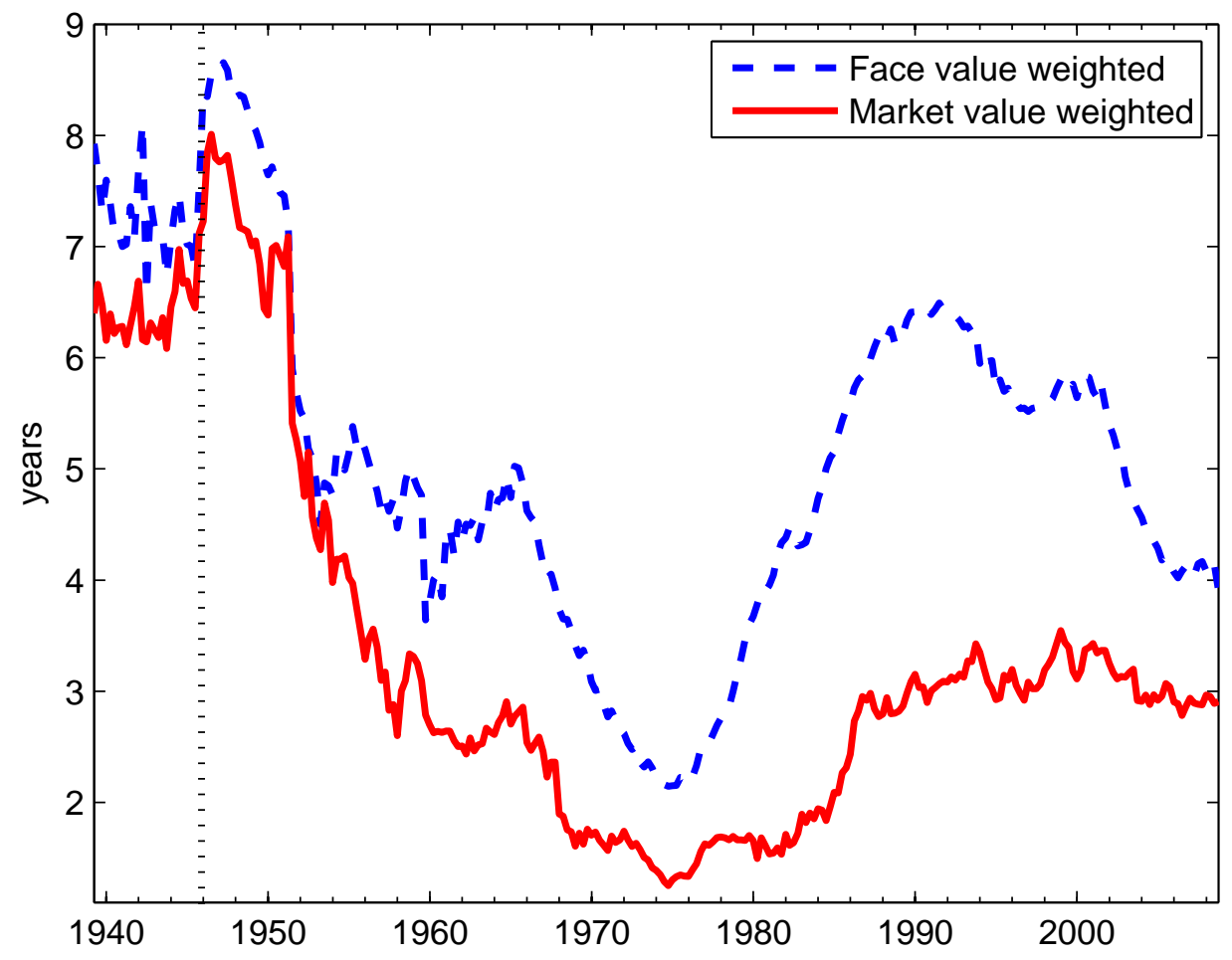

